\title{
Ramadan and Diabetes: A Narrative Review and Practice Update
}

\author{
Syed H. Ahmed (D) - Tahseen A. Chowdhury · Sufyan Hussain • \\ Ateeq Syed · Ali Karamat · Ahmed Helmy · Salman Waqar · \\ Samina Ali · Ammarah Dabhad · Susan T. Seal · Anna Hodgkinson • \\ Shazli Azmi · Nazim Ghouri
}

Received: June 11, 2020 / Published online: September 9, 2020

(C) The Author(s) 2020

\section{ABSTRACT}

Fasting in the Islamic month of Ramadan is obligatory for all sane, healthy adult Muslims. The length of the day varies significantly in temperate regions-typically lasting $\geq 18 \mathrm{~h}$ during peak summer in the UK. The synodic nature of the Islamic calendar means that

Digital Features To view digital features for this article go to https://doi.org/10.6084/m9.figshare.12624905.

Electronic Supplementary Material The online version of this article (https://doi.org/10.1007/s13300020-00886-y) contains supplementary material, which is available to authorized users.

S. H. Ahmed $(\varangle) \cdot$ S. T. Seal

Department of Endocrinology and Metabolic Medicine, Countess of Chester Hospital NHS

Foundation Trust, Chester, UK

e-mail: asyedharis76@gmail.com

\section{S. H. Ahmed}

School of Medicine, University of Liverpool, Liverpool, UK

T. A. Chowdhury

Department of Diabetes and Metabolism, Royal

London Hospital, London, UK

S. Hussain · A. Hodgkinson

Department of Diabetes and Endocrinology, Guy's

\& St Thomas' NHS Foundation Trust, London, UK

S. Hussain

Department of Diabetes, School of Life Course

Sciences, King's College London, London, UK
Ramadan migrates across all four seasons over an approximately 33-year cycle. Despite valid exemptions, there is an intense desire to fast during this month, even among those who are considered to be at high risk, including many individuals with diabetes mellitus. In this review we explore the current scientific and clinical evidence on fasting in patients with diabetes mellitus, focussing on type 2 diabetes mellitus and type 1 diabetes mellitus, with brief reviews on pregnancy, pancreatic diabetes, bariatric surgery, the elderly population and current practice guidelines. We also make recommendations on the management of diabetes patients during the month of Ramadan.

\section{S. Hussain}

Institute of Diabetes, Endocrinology and Obesity, King's Health Partners, London, UK

A. Syed · A. Karamat · A. Helmy

Department of Diabetes and Endocrinology,

University Hospitals Birmingham NHS Foundation

Trust, Birmingham, UK

S. Waqar

Nuffield Department of Primary Care Health

Sciences, University Oxford, Oxford, UK

S. Ali

NHS Greater Glasgow and Clyde, Glasgow, UK

\section{A. Dabhad}

Royal Wolverhampton NHS Trust, Wolverhampton, UK 
Many patients admit to a do-it-yourself approach to diabetes mellitus management during Ramadan, largely due to an under-appreciation of the risks and implications of the rigors of fasting on their health. Part of the issue may also lie with a healthcare professional's perceived inability to grasp the religious sensitivities of Muslims in relation to disease management. Thus, the pre-Ramadan assessment is crucial to ensure a safe Ramadan experience. Diabetes patients can be risk-stratified from low, medium to high or very high risk during the pre-Ramadan assessment and counselled accordingly. Those who are assessed to be at high to very high risk are advised not to fast. The current COVID-19 pandemic upgrades those in the high-risk category to very high risk; hence a significant number of diabetes patients may fall under the penumbra of the 'not to fast' advisory. We recognize that fasting is a personal choice and if a person chooses to fast despite advice to the contrary, he/she should be adequately supported and monitored closely during Ramadan and for a brief period thereafter. Current advancements in insulin delivery and glucose monitoring technologies are useful adjuncts to strategies for supporting type 1 diabetes patients considered to be high risk as well as 'high-risk' type 2 patients manage their diabetes during Ramadan. Although there is a lack of formal trial data, there is sufficient evidence across the different classes of therapeutic hypoglycaemic agents in terms of safety and efficacy to enable informed decision-making

A. Hodgkinson

NHS South East London Clinical Commissioning Group, London, UK

S. Azmi

Institute of Cardiovascular Science, University of Manchester, Manchester, UK

S. Azmi

Manchester Diabetes Centre, Manchester University

NHS Foundation Trust, Manchester, UK

N. Ghouri

Institute of Cardiovascular and Medical Sciences,

University of Glasgow, Glasgow, UK

N. Ghouri

Department of Diabetes and Endocrinology, Queen

Elizabeth University Hospital, Glasgow, UK and provide a breadth of therapeutic options for the patient and the healthcare professional, even if the professional advice is to abstain. Thus, Ramadan provides an excellent opportunity for patient engagement to discuss important aspects of management, to improve control in the short term during Ramadan and to help the observants understand that the metabolic gains achieved during Ramadan are also sustainable in the other months of the year by maintaining a dietary and behavioural discipline. The application of this understanding can potentially prevent long-term complications.

Keywords: COVID-19; Diabetes; Fasting; Iftaar; Ramadan; Suhoor; Technology; Type 1 diabetes; Type 2 diabetes

\section{Key Summary Points}

Fasting in Ramadan is obligatory for all adult, healthy and sane Muslims.

There are proven metabolic benefits of Ramadan fasting in healthy as well as diabetes patients.

Given the propensity of acute metabolic derangements and medicine-related sideeffects, patients with diabetes can be at significant health risk by fasting.

A pre-Ramadan risk stratification is crucial for diabetes patients, to guide and support the patients with informed decisionmaking.

High- to very high-risk patients are advised not to fast but if they choose to fast, they should be supported and monitored closely.

Pre-Ramadan assessment and education have been shown to improve the fasting experience of patients with diabetes. 
There is emerging evidence that newer technologies, such as insulin pump therapy, continuous glucose monitoring and hybrid closed-loop systems, can help type 1 diabetes patients and some evidence that flash glucose monitoring can help high-risk type 2 diabetes patients, fast with fewer complications.

In the current pandemic, patients in the low- or moderate-risk category, who are exposed to patients with confirmed COVID-19, are safe to fast as long as they are asymptomatic. Those who develop symptoms whilst fasting should be advised to break the fast.

\section{INTRODUCTION}

Fasting in the Islamic month of Ramadan is obligatory for all sane, healthy adult Muslims. Muslims refrain from eating, drinking and conjugal relations between dawn and sunset for 29-30 days during Ramadan, the ninth month of the Muslim lunar calendar. The synodic nature of the Muslin calendar means that Ramadan occurs 10-11 days earlier each Gregorian year, migrating across all four seasons over an approximately 33-year cycle. The length of the day varies significantly in temperate regions-typically lasting $\geq 18 \mathrm{~h}$ during peak summer in the UK [1].

As a general rule, a person observing fasting is not allowed any form of nutrition (including via a percutaneous endoscopic gastrostomy tube) and medication that involves administration via a mucosal route (i.e. oral, nasal or rectal). The use of topical, intramuscular and subcutaneous medications, such as insulin, is permitted and does not invalidate the fast [2]. It is traditional practice to have two meals over the 24-h period-Suhoor (also known as Sehri), the pre-dawn meal, and Iftaar, the sunset meal. Fasting is associated with beneficial changes to a person's general wellbeing [3].

Ultimately the decision to fast or otherwise rests with the individual concerned. Islam permits, and indeed supports, those with appropriate ailments to terminate the fast or be exempted from fasting, the two main options being:

- Making up the missed fast when health permits them to do so-either when the illness is no longer present, such as in acute illness, or when health is not worsened by fasting at another point in time (e.g. in the winter), in relation to chronic illness [1].

- An exemption from fasting in those whose illness will not permit them to keeping fasts indefinitely, this being replaced by a requirement to feed the poor.

Appropriate ailments that enable the above exemptions can also include old age or a condition which is stable, but which through fasting can adversely affect health or increase the risk of doing so $[1,4]$. This also includes abstaining from the use of medication that increases the risk of decompensation of chronic, but stable health conditions. Arriving at such decisions is based on the premise that the ailment will worsen, or recovery will be delayed or impaired by fasting, or a substantial fear that either may occur, which in turn can be determined by prior experience of fasting with the ailment, on common knowledge that this can happen or on the advice/opinion of an appropriate healthcare professional (HCP) [5]. Similarly, pregnant and breastfeeding mothers have the option to abstain from fasting if there is any concern for, or risk to, mother or baby. Muslims are encouraged, if they have any uncertainty regarding the various dispensations, to seek counsel from a religious authority.

Despite valid exemptions, there is an intense desire to fast during this month even among those who are considered to be at high risk, such as the elderly and multimorbid, including individuals with diabetes mellitus (DM) [6, 7]. Diabetes is classified into various forms of diabetes. These include the more common forms, such as type 2 (T2) diabetes, with its wide-ranging spectrums, type 1 (T1) diabetes, diabetes during pregnancy and gestational diabetes and pancreatic diabetes, and the less common forms, such as cystic fibrosis-related diabetes and maturity onset diabetes of the young (MODY). DM is a classic example of a condition in which individuals can be on a spectrum of disease severity, 
which would imply that there would be a spectrum of risk from fasting. Therefore, the religious and clinical advice being offered will have to be individualized and dependent on a multifactorial assessment of the patient. In this review we explore the current scientific and clinical evidence on fasting in patients with diabetes, focusing on T2 diabetes, T1 diabetes and guidance on pregnancy and pancreatic diabetes, as well as current practical guidelines. We also make recommendations on the management of diabetes patients during the month of Ramadan.

This article is based on previously conducted studies and does not contain any studies with human participants or animals performed by any of the authors.

\section{METHODS}

We undertook a narrative review of current literature on fasting during Ramadan for patients with diabetes. We performed a literature search of various databeses, including PubMed, Google Scholar, CiNAHL, among others using the search terms "diabetes", "type 2 diabetes", "Ramadan" and "fasting" in various combinations. A number of publications were retrieved, covering the spectrum from observational studies, randomized controlled trials (RCT), systematic, non-systematic and thematic reviews to practice and management guidelines published by group of authors with a renowned publication history on this topic. Whilst the majority of research and focus in this review relates to $\mathrm{T} 2$ diabetes, other forms of diabetes, including $\mathrm{T} 1$ diabetes, are briefly discussed.

\section{PHYSIOLOGY AND PATHOPHYSIOLOGY OF FASTING AND THE EFFECTS OF RAMADAN FASTING IN HEALTHY INDIVIDUALS}

\section{Normal Physiology}

In healthy individuals, the insulin level rises in response to blood glucose levels, leading to glucose disposal by glycogen synthesis in the liver and muscle and inhibition of glycogenolysis and gluconeogenesis (Fig. 1). Within the first few hours of fasting, as glucose levels fall, insulin secretion is suppressed. When the plasma glucose levels fall below the physiological range (3.6$3.9 \mathrm{mmol} / \mathrm{L}[65-70 \mathrm{mg} / \mathrm{dL}])$, the counterregulatory hormones glucagon and epinephrine are secreted. Hepatic glycogenolysis stimulated by glucagon and epinephrine serves to maintain blood glucose level within the physiological range. As fasting progresses, with a progressive rise in glucagon and epinephrine, glucose metabolism switches to a combination of glycogenolysis and gluconeogenesis whereby de novo glucose is synthesized from glycerol and amino acid residues. It takes about $12-36 \mathrm{~h}$ for the hepatic glycogen levels to be depleted, following which fatty acids from the adipose tissue are mobilized to form ketone bodies which serve as fuel for vital organ function, preserving glucose for utilization by the brain and erythrocytes (Fig. 2).

Typically, after $12-36 \mathrm{~h}$ of fasting, when liver glycogen stores are depleted, a metabolic switch occurs, resulting in lipolysis and the production of free fatty acids and glycerol. Free fatty acids released into the blood stream undergo betaoxidation in the liver to produce the ketones, beta-hydroxybutyrate ( $\beta$-OHB) and acetoacetate. These are utilized by the brain, muscle cells other tissues for energy and serve to preserve lean muscle mass, improve body composition, optimize physiological function and slow ageing and disease processes [8].

\section{Altered Physiology of Fasting in Diabetes}

Depending on the subtype of diabetes, there are varying degrees of defects in insulin and glucagon secretion and insulin resistance, with the potential for serious glycaemic consequences (Fig. 3). For those with T2 diabetes at the less severe end of the spectrum, primary defects are in insulin resistance; however, with disease progression in the form of beta-cell failure and greater insulin deficiency, a phenotype closer to T1 diabetes may become more apparent [9]. Insulin resistance prolongs the time to "flip the metabolic switch", which implies that it may 


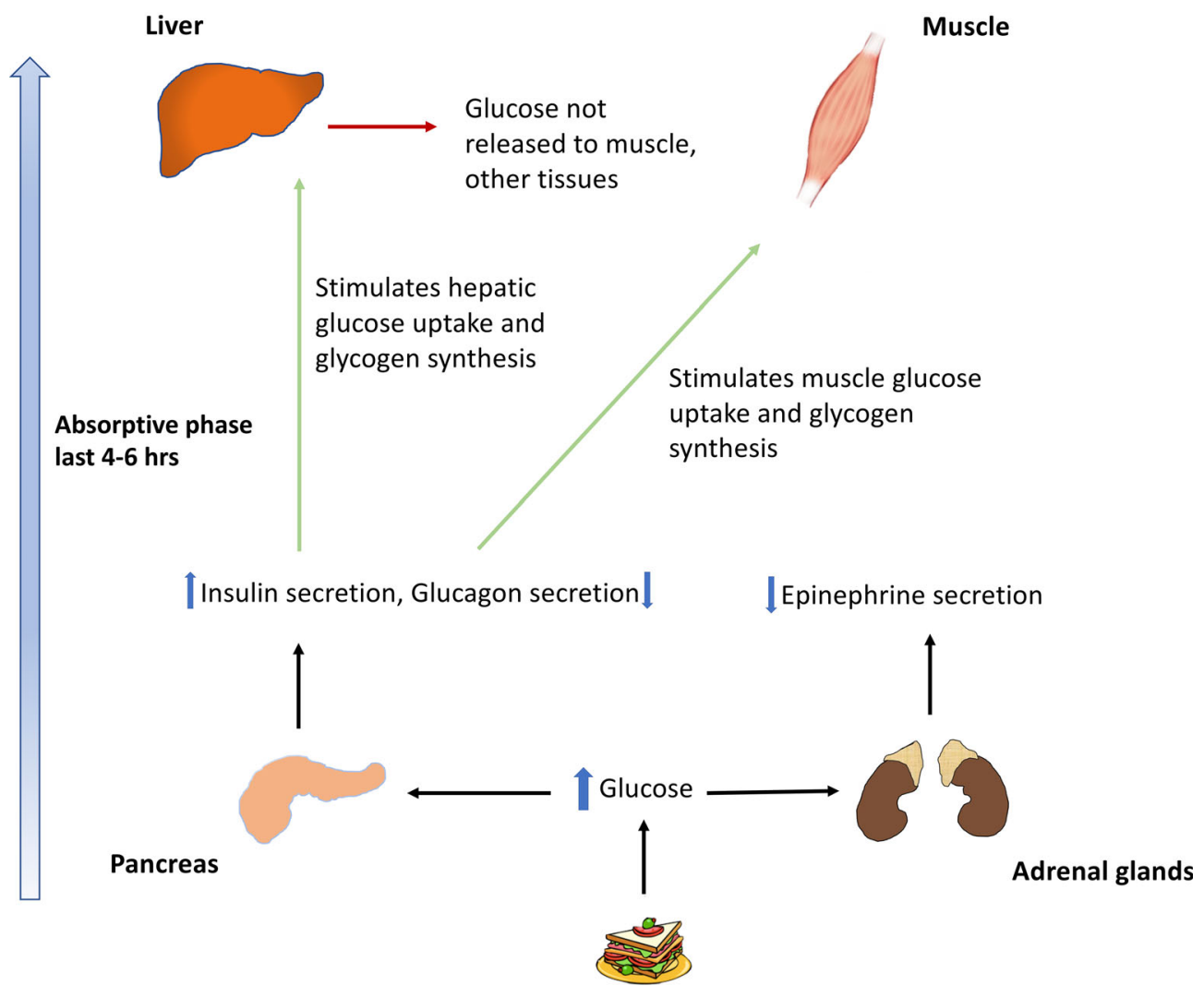

Fig. 1 Physiology of glucose metabolism in the fed state

take longer to generate fatty acid for energy and other metabolic benefits [8]. In early $\mathrm{T} 2$ diabetes, fasting or very low calorie diets and controlled fasting associated with modest weight loss can have favourable effects on the early pathophysiological components of insulin resistance and adiposity and normalize blood sugars, i.e. reverse the T2 diabetes phenotype $[10,11]$.

However, in potentially very advanced forms of T2 diabetes and, more importantly, in T1 diabetes patients, due to absolute insulin deficiency, there is a theoretical risk of clinically significant ketogenesis and significant hyperglycaemia in the absence of exogenous insulin. In addition to this, impaired counterregulatory responses to hypoglycaemia along with the inability to decrease circulating insulin of exogenous origin and reduction in the adrenal and sympathetic neural tone, there is potential for severe hypoglycaemia [12]. In patients with poor control manifested by chronic hyperglycaemia, the plasma threshold for the secretion of counterregulatory hormones is elevated and is the converse of that in patients with recurrent hypoglycaemia, for example in patients who maintain tight diabetes control $[13,14]$. Hyperglucagonaemia in T2 diabetes is a well-recognized contributor to hyperglycaemia by stimulating increased hepatic production, but the risk of ketoacidosis is low due to the relative presence of insulin $[15,16]$. The effects of intermittent fasting on glucagon levels in $\mathrm{T} 2$ diabetes have not been formally studied.

A study on 56 patients using continuous glucose monitoring (CGM), of which 50 patients had T2 diabetes and 6 had T1 diabetes, compared the profiles using the combined dataset between Ramadan and non-Ramadan periods and found statistically significant differences in variability at different time points in mean glucose profiles, over a 24-h period (Fig. 4). A rapid rise in glucose was observed after Iftaar, which could be explained by the 


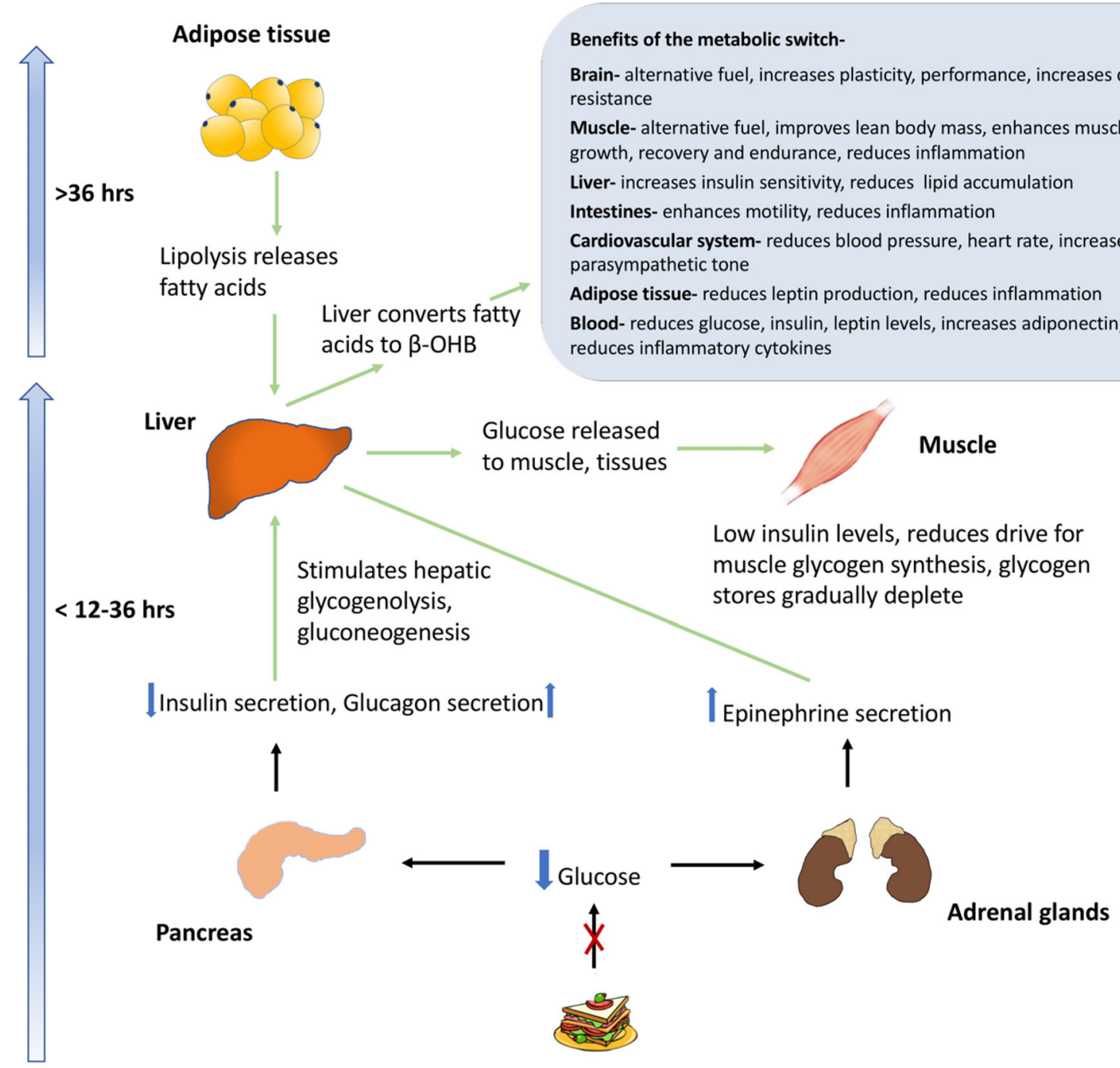

Fig. 2 Physiology of fasting in a healthy individual. $\beta$-OHB Beta-hydroxybutyrate

high glycaemic index and quantity of the meal, timing of intake of the diabetes medications (taken just before or after a meal) and hormonal changes from prolonged fasting [17].

\section{METABOLIC EFFECTS OF CONTROLLED AND RAMADAN FASTING}

A wide range of metabolic benefits from Ramadan fasting has been described in the literature. The eating pattern during Ramadan fasting conforms to the definition of time restricted feeding (TRF), which is one form of intermittent fasting [8]. Intermittent fasting can be a means of "flipping the metabolic switch" that can serve to preserve lean muscle mass, improve body composition, optimize physiological function and slow ageing and disease processes [8]. A study of TRF in overweight humans showed up to a $4 \%$ weight loss over 16 weeks that was sustained for $>1$ year and improvement in sleep pattern and daytime alertness [18].

Studies have shown that in the final week of Ramadan there is a reduced rate of oxygen consumption $[19,20]$ and lower resting heart rate $[20,21]$, indicating a slowing of metabolism. There is also reduced submaximal exercise oxygen consumption $[21,22]$ and heart rate 


\section{Adipose tissue}

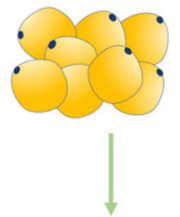

Lipolysis accelerated in T1DM in absence of supplemental insulin; lipolysis may be delayed in T2DM due to IR

Liver

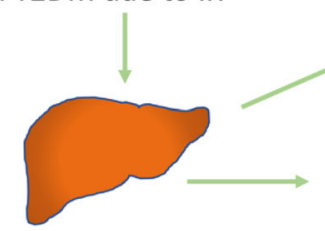

Glucose released to muscle, tissues, impaired utilization due to lack of insulin in T1DM, IR in T2DM
The metabolic switch is delayed in T2DM, due to IR. However after repeated IF, IR drops, and sensitivity improves, leading to metabolic gains.
Stimulates hepatic glycogenolysis and gluconeogenesis

$\uparrow$

Insulin secretion impaired or $\widehat{\}$ secondary to IR in T2 DM Chronically glucagon in T2DM No insulin secretion, Glucagon secretion impaired in T1DM

Pancreas
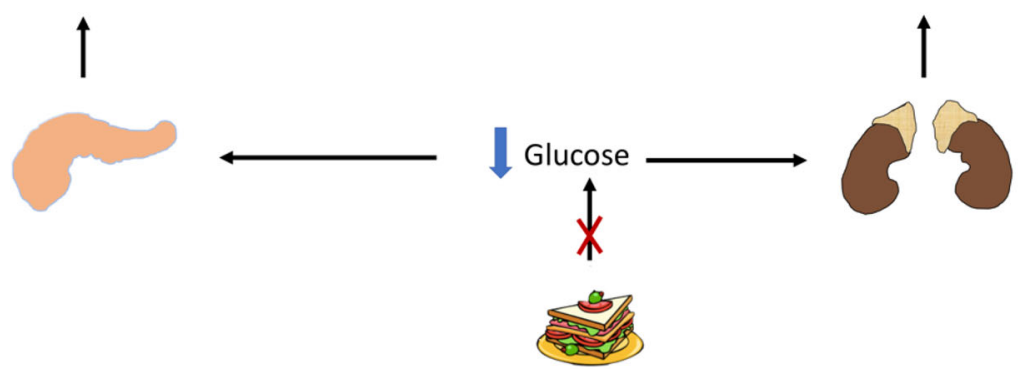

Absence of insulin levels in T1DM, IR in T2DM reduces drive for muscle glycogen synthesis, glycogen stores gradually deplete

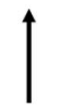

Epinephrine secretion impaired in T1DM and advanced T2DM

Fig. 3 Pathophysiology of fasting in diabetes patients. $I F$ intermittent fasting, $I R$ insulin resistance, $T 1 D M$ type 1 diabetes mellitus, $T 2 D M$ type 2 diabetes mellitus

[23]. Fuel selection at rest [19] and during submaximal exercise favours lipid oxidation [23].

Ramadan fasting has been shown to induce a significant reduction in fat percentage in overweight and obese people [24], leading to weight loss [24, 25]. Weight loss is more significant in those who fast throughout Ramadan [26]. Furthermore, a cross-sectional study investigating the impact of Ramadan fasting on inflammatory cytokines, immune biomarkers and anthropometric measurements has shown a significant reduction in interleukin $1 \beta$, interleukin-6, tumour necrosis factor alpha, systolic and diastolic blood pressures, body weight and body fat percentage (at the end of the third week of Ramadan) [27].

There is growing evidence that short-term fasting can improve patient response to cancer chemotherapy, whilst providing protection from toxicity [28].

Habbal et al. studied the variations in blood pressure during the month of Ramadan in a small cohort and found that the variations are minimal [29]. Perk et al. found no change in ambulatory blood pressure before [30] and during Ramadan, while Ural et al. found no statistically significant difference between 24-h blood pressure monitoring of hypertensive 


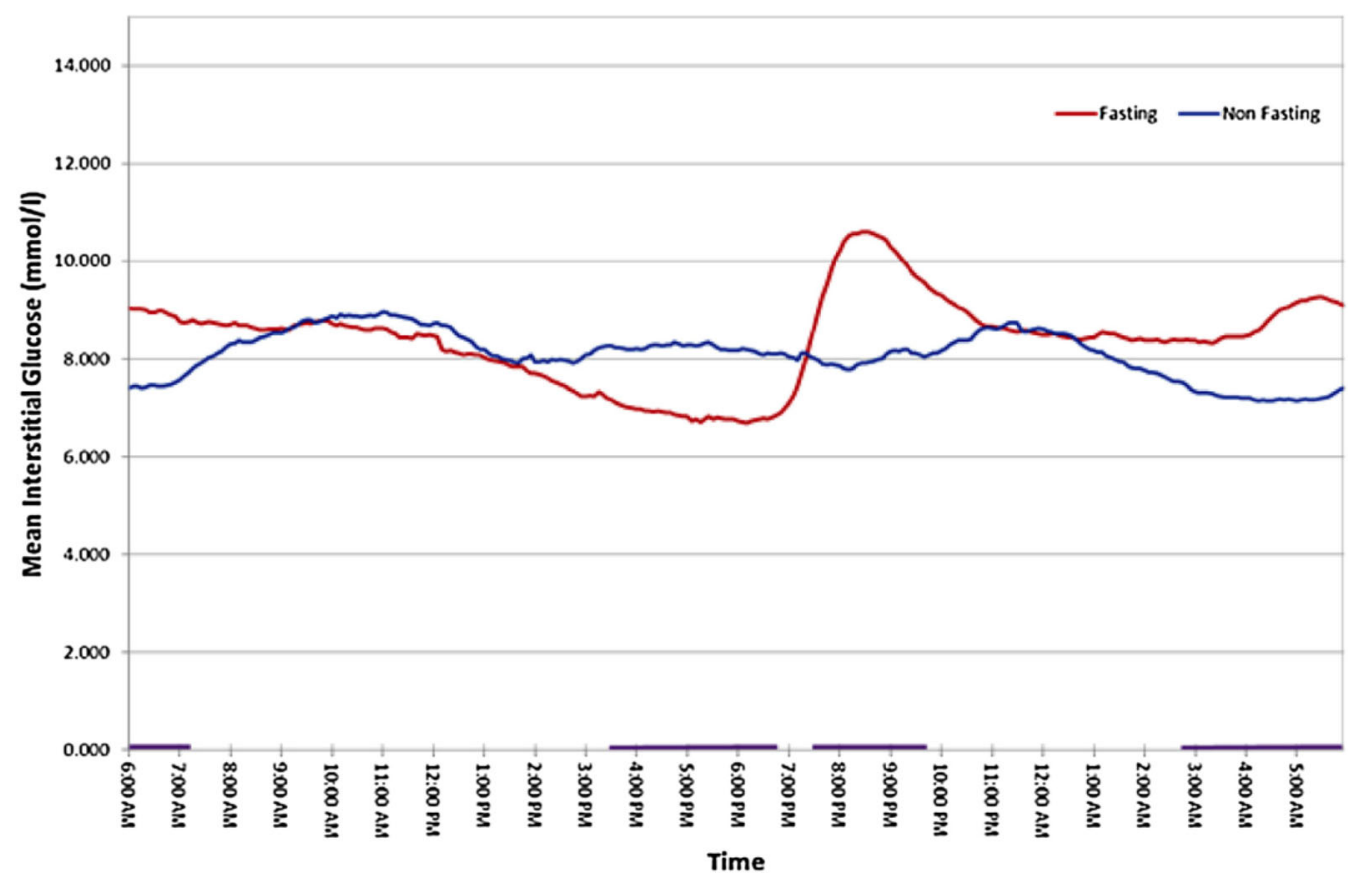

Fig. 4 Mean 24-h continuous glucose monitoring (CGM) profiles derived from all patients with diabetes $(n=56)$ during Ramadan (Fasting) and non-Ramadan (Non-fasting) periods. The purple bars along the $x$-axis at the bottom of the graph depict periods when the difference between the two

patients on combination drug therapy during and 1 month after Ramadan [31].

One study reported a lower adiponectin level, elevated morning leptin levels and lowered evening growth hormone levels in Ramadan practitioners in Saudi Arabia [32]. Higher adiponectin levels are associated with improved insulin sensitivity. Conversely, another study showed increase in adiponectin at the end of Ramadan [33]. These changes may be due to changes in meal and sleeping patterns during Ramadan. There have been no studies looking at these levels in fasting diabetes patients, thus no meaningful conclusions can be drawn.

Finally, the effect of the changes in the sleep pattern as dictated by the timing of the Suhoor meal or dawn meal have been studied. Typically, Muslims wake up between 0200 and 0600 hours for the meal, depending on the geographical latitude and time of the year. After the meal they may go back to sleep or remain awake. There is possible decreased total sleep time (particularly if an afternoon or evening states is large and significant* Reprinted from Diabetes Metab, Vol 41, Lessan et al, Glucose excursions and glycaemic control during Ramadan fasting in diabetic patients: Insights from continuous glucose monitoring (CGM), pp28-36, Copyright (2015), with permission from Elsevier [17]

nap is not had), delayed sleep onset and decreased proportion of rapid eye movement (REM) sleep. There is a known medical correlation between sleep duration and insulin resistance. Circadian patterns of hormonal secretion that are generally sleep-entrenched are altered due to changes in the sleeping and eating patterns as well as by fasting. One study showed an inversion of the cortisol secretion pattern with lower morning cortisol and higher evening cortisol levels by day 7 of Ramadan, reverting to near baseline by day 21 (Fig. 5) [34].

\section{EPIDEMIOLOGICAL OBSERVATIONAL DATA OF DIABETES MELLITUS AND RAMADAN, AND LANDMARK STUDIES}

The estimated global prevalence of diabetes as of 2019 is approximately 463 million adults, 


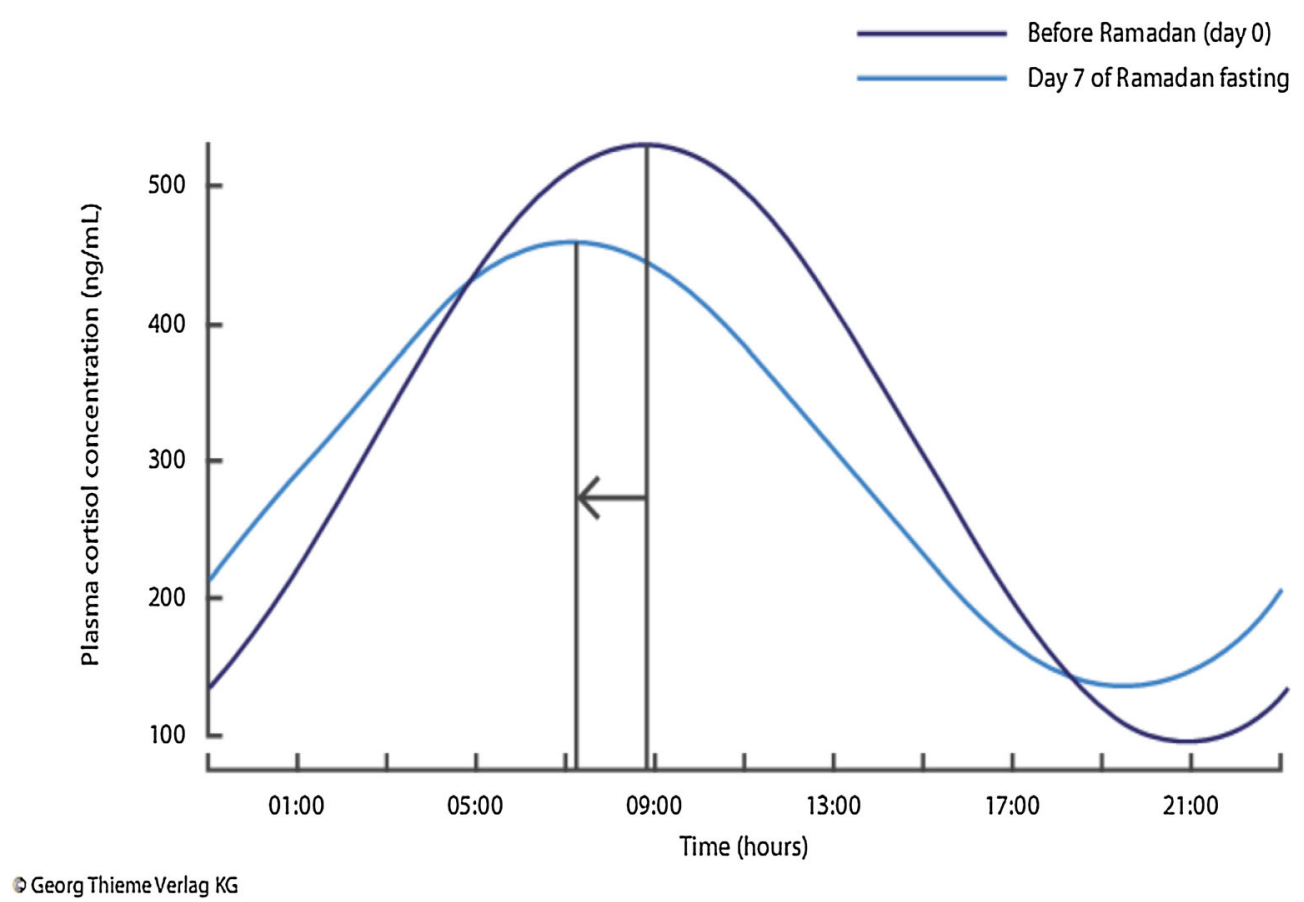

Fig. 5 Changes in cortisol circadian rhythm during Ramadan showing a shift in the cortisol profile on day 7 and a return to near baseline (non-Ramadan) values by day 21

which is expected to rise to 700 million by 2045 [35]. India, Egypt, Indonesia and Bangladesh are among the top ten countries with the highest prevalence of adults with diabetes-each with Muslim populations in excess of 100 million [36]. The population of Muslims across the world in 2015 was estimated at 1.8 billion, accounting for $24 \%$ of the global population; this is projected to increase to 3 billion in 2060, accounting for $31 \%$ of the world population [37]. Rapid urbanization [38], calorie-dense nutrition [39] and sedentary lifestyles contribute to excess weight, which in turn increases the risk of diabetes [40]. It is worth noting here that much of the published data are based on studies of $\mathrm{T} 2$ diabetes patient populations exclusively or on studies of a T2 diabetes-dominant study cohort with the results combining data on $\mathrm{T} 1$ diabetes patients with the main findings. Furthermore, even if $\mathrm{T} 1$ diabetes data are presented, there is also the possibility of misclassifying a patient on insulin therapy as having T1 diabetes, especially given the increased prevalence of obesity in Muslim populations [41]. Such confounding factors may also contribute to the findings being less accurate in the context of making specific comments on $\mathrm{T} 1$ diabetes and Ramadan.

The landmark Epidemiology of Diabetes and Ramadan (EPIDIAR) study found that as many as $42.8 \%$ of the 1080 patients with T1 diabetes and $78.7 \%$ of the 11,173 patients with $\mathrm{T} 2$ diabetes reported fasting for at least 15 days during Ramadan [7], leading to an estimation that approximately 120 million people with diabetes worldwide fast during Ramadan. Approximately half of these patients did not change their lifestyle, sleep duration, food or fluid intake and sugar intake and the majority did not alter their medications. The study revealed that fasting in Ramadan was associated with significant hypoglycaemia. It must be noted that even though the study excluded over 600 patients with T1 diabetes at screening as it was felt their diagnosis was inaccurate, of the remaining 1000+ patients, 3\% were taking a sulphonylurea (SU) to manage their condition. Thus, it is possible that within the $\mathrm{T} 1$ diabetes cohort, there could be many more who may have $\mathrm{T} 2$ diabetes or another form of diabetes. Nonetheless, the results of this study highlight the challenges that patients and HCPs face in diabetes 
management during Ramadan and present the window of opportunity for engagement prior to and during Ramadan to make fasting a safe and healthy experience. On the back of this study, the American Diabetes Association (ADA) published their first recommendation for the management of diabetes in 2005 [42]. The publication was pioneering, and the recommendations have been widely adopted across the globe and reproduced in subsequent and more recent national and independent guidelines [43-47]. It is important that we acknowledge that whilst the EPIDIAR study has been fundamental in shaping guidance on fasting and Ramadan, it was conducted in the early 2000s in Asian and Middle Eastern countries where access to health services and the latest diagnostic, monitoring treatment options for diabetes were limited.

Another important international observational study, CREED, provided further insight into the management and outcomes of patients with T2 diabetes during Ramadan [6, 48]. Physicians $(n=508)$ across 13 countries enrolled patients with $\mathrm{T} 1$ diabetes, $\mathrm{T} 2$ diabetes or gestational diabetes in the study, and data were reported for 3250 patients with T2 diabetes. Analysis of the data revealed that $94.2 \%$ of these patients reported fasting for at least 15 days during Ramadan and that $63.6 \%$ reported fasting every day during the month, indicating that many patients considered to be at high or very high risk of adverse events still fast during Ramadan. The findings of CREED were used to update the 2010 iteration of the ADA recommendations for diabetes in Ramadan [43]. More recent updates from CREED have impacted on recent guidance $[47,48]$.

More recently, the DAR-MENA study (2019) showed that despite the risks associated with fasting for people with $\mathrm{T} 1$ diabetes, almost onehalf of participants in the study fasted for the full 30 days of Ramadan with no significant change in hypoglycaemic events [49]. This prospective study is the first to describe the characteristics and care of participants with T2 diabetes during Ramadan in the Middle East and North Africa (MENA) area, and the results can be utilized in the development of evidence- based care to ensure the safety of participants who fast [50].

\section{SPECIFIC RISKS AND METABOLIC PARAMETERS IN DIABETES IN RELATION TO RAMADAN FASTING}

Patients in preparation for Ramadan may make changes to their treatment of their own accord or on the advice of the HCPs. It is known that many Muslim patients do not approach their HCP with the concern that they may be advised not to fast [51]. Inadequate pre-Ramadan preparation, poor prior engagement with the HCP, baseline suboptimal control and the stress associated with fasting due to disturbances in the eating patterns, sleep-wake cycles and intercurrent illness are all factors that can adversely affect the fasting experience.

Potential risks associated with fasting and diabetes are disturbance in glycaemic control manifesting as hypoglycaemia and hyperglycaemia and metabolic emergencies, such as diabetic ketoacidosis (DKA), hyperosmolar hyperglycaemic syndrome (HHS), dehydration, renal impairment and hypotension and thrombosis secondary to hyperglycaemia and dehydration. Further, cardiometabolic factors such as blood pressure and lipid profiles may also be subject to influence from Ramadan fasting.

\section{Glycaemic Control}

In a meta-analysis carried out by Aydin et al., Ramadan fasting was not associated with any significant negative effects on postprandial (plasma) glucose or fructosamine levels. However, body mass index (BMI), glycated haemoglobin $\left(\mathrm{HbA}_{1 \mathrm{c}}\right)$ and fasting plasma glucose were significantly decreased [52].

A narrative literature review of all peer-reviewed publications looking at the health implications of Ramadan fasting was undertaken in 2018 [53]. The majority of studies reviewed suggested that under normal circumstances, Ramadan fasting was safe for persons 
with mild and stable medical conditions. However, the authors highlighted the need for individualized management of high-risk patients.

\section{Hypoglycaemia}

In the EPIDAR study patient cohort, severe hypoglycaemia requiring hospitalization increased during Ramadan by 4.7-fold in patients with T1 diabetes (3-14 events/100 people/month) and by 7.5 -fold in those with T2 diabetes (0.4-3 events/100 people/month) [7]. With the advent of newer antihyperglycaemic agents, such as second-generation SUs, glucagon-like peptide-1 (GLP-1) analogues, insulin analogues and sodium-glucose transporter-2 (SGLT-2) inhibitors, the rates of severe and nonsevere hypoglycaemia are fewer [54-60]. Aldawi et al. found significant increases in the mean amplitude of glycaemic excursions during early Ramadan between patients on two or more antidiabetic medicines and those on SUs [61]. Earlier research also supports the greater risk of hypoglycaemia with SUs compared metformin monotherapy [62]. A number of studies have also shown the lower risk of hypoglycaemia with newer T2 diabetes therapies compared to SUs and their safety in Ramadan fasting [58, 59, 63-71].

\section{Hyperglycaemia and Ketoacidosis}

The EPIDIAR study showed that during Ramadan the rate of hospitalization for severe hyperglycaemia increased significantly from 1 to 5 events/100 people/month $(p<0.0001)$ in patients with T2 diabetes; for those with T1 diabetes, hospitalization for severe hyperglycaemia (with or without ketoacidosis) increased non-significantly from 5 to 16 events/100 people/month $(p=0.1635)[7,43]$. In patients with T1 diabetes, there was a non-significant increase in ketoacidosis in patients with poor control prior to Ramadan.

A number of studies examining the risk of DKA in T1 diabetes patients have found no increased risk [72-75]. An observational study by Al-Agha et al. suggests that flash glucose monitoring enabled children who wished to fast to be able to do so without experiencing severe hypoglycaemia or DKA [74]. A prospective study in $\mathrm{T} 1$ and $\mathrm{T} 2$ diabetes patients showed that active glucose monitoring, adjustment of medications, dietary counselling and patient education significantly reduced the risk of acute diabetic complications in fasting patients [76].

In patients with $\mathrm{T} 2$ diabetes, the risk of ketoacidosis is minimal during fasting, as demonstrated by a retrospective analysis of records of T1/T2 diabetes patients $[77,78]$ and prospective observational studies undertaken in patients with T2 diabetes $[79,80]$. Earlier publications, not supported by evidence, suggested an increased risk of DKA during Ramadan. Beshyah and colleagues evaluated the validity of the perceived increased risk and the actual occurrence of DKA during fasting in Ramadan in a non-systematic, narrative review of literature and found that the risk of DKA was not increased during fasting [81]. Consequently, these authors de-emphasized the earlier proposed risk of DKA during Ramadan, creating a more balanced approach for those wishing to fast during Ramadan.

Alabbood and colleagues performed a literature review of 16 studies that had studied the effects of Ramadan fasting on glycaemic control in $\mathrm{T} 1$ diabetes and $\mathrm{T} 2$ diabetes patients [82]. Three studies in $\mathrm{T} 1$ diabetes/T2 diabetes combined cohorts found significant improvements in two glycaemic parameters: fructosamine and $\mathrm{HbA}_{1 \mathrm{c}}[17,55,83]$. Three other studies in T1/T2 diabetes patients recorded complications, such as severe hyperglycaemia, severe hypoglycaemia (which required help from others) and DKA in insulin-dependent patients [54, 72, 76]. One study found that short-acting analogues may be advantageous pre-meal, as insulin lispro was found to be associated with lower glucose excursions $2 \mathrm{~h}$ post Iftaar [72]. A randomized, open-label, crossover study also found that pre-mixed preparations containing insulin lispro were superior to those containing human insulins [54]. The authors of this review suggested that Ramadan fasting can be feasible for T1 diabetes and T2 diabetes patients on insulin. CGM-enhanced insulin pump therapy and rapid-acting 
insulin like lispro or pre-mixed insulins containing lispro may be advantageous when compared to human-soluble or pre-mixed human insulin, respectively.

\section{Dehydration, Thrombosis and Macrovascular Risk}

Fasting in countries with hot climates and prolonged periods of fasting ( $\geq 18 \mathrm{~h}$ in countries in the temperate regions during summer) can put patients at risk of dehydration, which can be exacerbated by uncontrolled hyperglycaemia leading to osmotic diuresis. In patients with T2 diabetes, dehydration can present as low blood pressure, lethargy, syncope, haemoconcentration and hypercoagulability predisposing to thrombosis [84] and strokes [85]. Although fasting can reduce platelet sensitivity to clopidogrel in T2 diabetes, this may be related to an increase in glycaemia during Ramadan [86]. However, it has been reported that the incidence of acute cardiac illness in patients with $\mathrm{T} 2$ diabetes is not different during Ramadan than at other times [87].

A prospective study was conducted into the safety of Ramadan fasting in T2 diabetes patients with cardiovascular heart disease (CHD) [88]. CGM was carried out using FreeStyle Libre ${ }^{\circledR}$ monitoring devices (Abbott Laboratories, Chicago, IL, USA). During fasting a significant improvement was seen in $\mathrm{HbA}_{1 \mathrm{c}}$, but a higher incidence and prolonged duration of hypoglycaemia was seen compared to non-fasting. Lipid profile, BMI, renal function and systolic and diastolic blood pressure were not significantly altered. The authors concluded that in patients with stable CHD who were receiving optimal diabetes care, no adverse cardiovascular effects were associated with Ramadan fasting.

The authors of a systematic review of the effect of Ramadan fasting on cardiovascular events and risk factors in patients with T2 diabetes found insufficient evidence to link Ramadan fasting with increased or reduced incidence of cardiovascular events in people with diabetes, although there was some indication that stroke risk may be increased [89]. Findings were noted to be inconsistent in terms of risk factors, as some favoured Ramadan fasting, and others did not.

\section{Body Weight}

The effect of Ramadan fasting on anthropometric parameters was studied by Khaled and colleagues [167]. These authors reported weight loss and a decrease in calorie intake during the month of Ramadan. In a large cross-sectional study, T2 diabetes patients showed an improvement in metabolic parameters, including BMI, during fasting in Ramadan [168].

The DAR-MENA T2 diabetes trial confirmed statistically significant improvement in weight and total waist circumference in people with T2 diabetes fasting during Ramadan [50], whilst the authors of a subsequent systematic review and meta-analysis concluded that Ramadan fasting was associated with statistically significant consistent-albeit transient-reductions in weight and fat mass, especially in people who are overweight or obese [20].

\section{Blood Pressure Control}

Samad et al. found a significant drop in both systolic and diastolic blood pressure (SBP and DBP, respectively) in normotensive males before and during Ramadan fasting [90], while Norouzy et al. found no significant difference in the trend of 24-h blood pressure monitoring before, during and after Ramadan in normotensive and hypertensive volunteers [91]. A significant reduction in both SBP and DBP was shown by Salahuddin et al. in an observational trial involving hypertensive patients on antihypertensive therapy [92]. Previous findings were discussed by Mazidi et al. in a systematic review [93], while Hassanein et al. found improvement in blood pressure (statistically significant for SBP and non-statistically significant for DBP) in a large international, multicentre, prospective, observational trial [50].

\section{Lipid Profile}

Metabolic parameters, including lipid profile, have been studied in people with diabetes fasting during Ramadan. Bouguerra et al. found a negative correlation between cholesterol intake during Ramadan and the change in high- 
density lipoprotein-cholesterol (HDL-C), which increased by $13 \%$ at the end of Ramadan and by 23\% 3 weeks after Ramadan [94].

A progressive and significant increase in HDL-C was found by Shahab et al., in addition to a significant decrease in total triglycerides and low-density lipoprotein-cholesteral (LDL-C) but not in total cholesterol [95]. Similar findings were reported in relation to HDL-C and LDL-C by Norouzy et al. [79]. The results of the DAR-MENA T2 diabetes trial confirmed significant improvements in LDL-C and total cholesterol in people with T2 diabetes fasting in Ramadan [50].

\section{MANAGEMENT}

\section{General Guidance and Risk Stratification}

The International Diabetes Federation (IDF) and Diabetes and Ramadan (DAR) Practical Guidelines (2016) provide HCPs with relevant background information and practical recommendations, enabling them to help people with diabetes participate in fasting during Ramadan, while minimising the risk of complications [36]. The IDF-DAR Practical Guidelines adopt a three-tiered risk stratification matrix, with patients stratified to the very highor high-risk groups being advised not to fast, and are a well-accepted stratification that can be applied for people with diabetes prior to Ramadan fasting. The guidance highlights the general consensus among religious authorities and scholars that if an individual is considered to be at high to very high risk then they should refrain from fasting [4]. A more detailed exposition pertaining to the religious obligation of fasting and practical considerations in relation to health and illness with particular consideration to diabetes has been published elsewhere by authors of this review [96]. A risk-stratification matrix adapted from IDF-DAR by the South East London Area Prescribing Committee is shown in Table 2 [97]. This matrix also includes coronavirus disease 2019 (COVID-19) as a risk factor in the context of the current pandemic. Further below, there is linked commentary explaining this in detail.
Diabetes patients wishing to observe the fast are advised to attend a pre-Ramadan assessment with their HCP at least 6-12 weeks before the start of Ramadan (Fig. 6). Factors to be taken into consideration during the assessment for the purpose of risk stratification are type of diabetes, ongoing diabetes treatment, degree of diabetes control, individual propensity for hypoglycaemia, competence at self-management, previous Ramadan experience, presence of diabetes complications and co-morbidities, ongoing or recent intercurrent illness, degree of frailty, level of cognition, polypharmacy burden, occupation and social circumstances (Table 1).

After risk stratification, when the patient makes an informed decision to fast, an individualized management plan should be developed (Table 2). The decision may contradict medical advice, but patient choice should be respected, and patients should be supported by HCPs on the management of their diabetes. Key aspects to be covered during the consultation(s) in preparation for fasting are given in Table 3.

The current DAR guidance for patients with $\mathrm{T} 1$ diabetes or $\mathrm{T} 2$ diabetes on insulin who are classed as having a high or very risk and (strongly) advises these patients not to fast. The EPIDIAR study suggests that despite this advice from HCPs, about $40 \%$ with T1 diabetes continued to fast [5]. Findings from previous studies that have been summarized in the latest DAR guidance suggest that only half of patients receive any form of counselling or advice regarding fasting [36].

With the correct advice and support from HCPs, many people with T2 diabetes may be able to fast safely during Ramadan. Patients taking metformin, SUs or insulin will need to adjust dose and/or timings to reduce the risk of complications [97]. Guidance on dose adjustments for oral and injectable therapies, including insulin, are given in Tables 4 and 5. Newer antiglycaemic medications, including incretinbased therapies, are associated with a lower risk of hypoglycaemia and may be preferable for use during Ramadan.

Thus, to conclude a patient's decision to fast should be made after ample discussion with his 


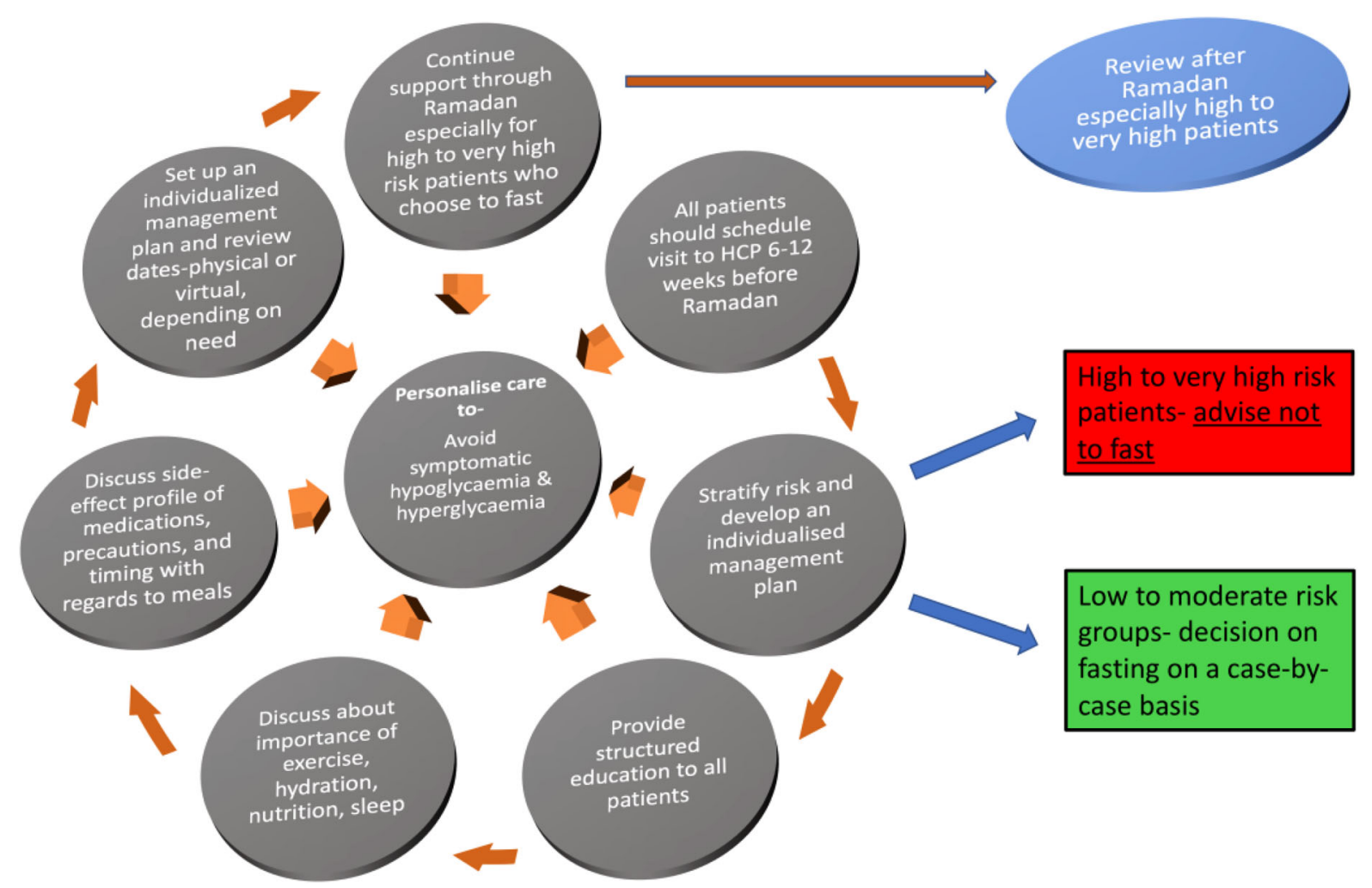

Fig. 6 Pre-Ramadan assessment and plan of care

Table 1 Factors to consider for risk stratification

\section{Factors}

Type of diabetes

Ongoing diabetes treatment

Degree of diabetes control

Individual propensity for hypoglycaemia

Competence at self-management

Previous Ramadan experience

Presence of diabetes complications and co-morbidities

Ongoing or recent intercurrent illness

Degree of frailty

Level of cognition

Polypharmacy burden

Occupation

Social circumstances or her physician or nurse, concerning the risks involved and further discussion with a religious authority if appropriate. Patients who insist on fasting should undergo pre-Ramadan assessment and receive appropriate education and instructions related to physical activity, meal planning, glucose monitoring, and dosage and timing of medications. The management plan must be highly individualized. Patients classified as very high or high risk, including those with $\mathrm{T} 1$ diabetes and pregnant women with diabetes, need close medical supervision if they insist on Ramadan fasting. Further, if physicians still have reservations about their patients fasting, particularly those on insulin, particularly when the fasts are longer in the summer in temperate regions, one valid option from a religious perspective is to defer the fast to the winter when the duration is shorter and the risks of hypoglycaemia and dehydration are likely to be [1]. Similarly, another option is to consider trial fasting in the month before 
Table 2 Risk stratification for patients with diabetes

\begin{tabular}{|c|c|c|}
\hline $\begin{array}{c}\text { Risk category and Religious } \\
\text { Opinion of Fasting a }\end{array}$ & Patient Characteristics & Comments \\
\hline $\begin{array}{l}\text { Category 1: very high risk } \\
\text { Advise MUST NOT fast }\end{array}$ & 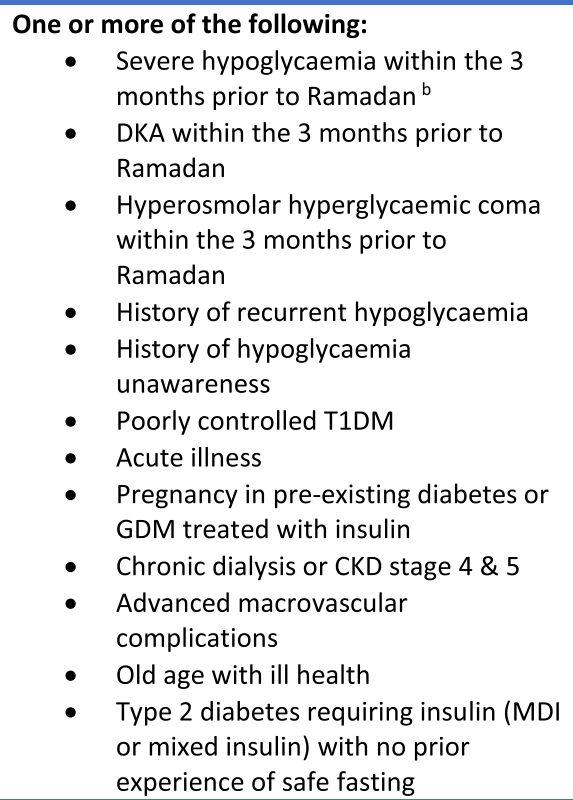 & \multirow{2}{*}{$\begin{array}{l}\text { If patients wish to fast, they should be } \\
\text { supported and should: } \\
\text { - } \quad \text { Receive structured education } \\
\text { - } \text { Be followed by a qualified } \\
\text { - } \quad \text { Check their blood glucose } \\
\text { regularly (SMBG) } \\
\text { - } \quad \text { Adjust medication dose as per } \\
\text { recommendations } \\
\text { - Be prepared to break the fast } \\
\text { in case of hypo-or } \\
\text { hyperglycaemia } \\
\text { Be prepared to stop the fast in } \\
\text { case of frequent hypo-or } \\
\text { hyperglycaemia or worsening } \\
\text { of other related medical } \\
\text { conditions }\end{array}$} \\
\hline $\begin{array}{l}\text { Category 2: high risk * } \\
\text { Advise should NOT fast }\end{array}$ & $\begin{array}{l}\text { One or more of the following: } \\
\text { - } \quad \text { T2DM with sustained poor glycaemic } \\
\text { control c } \\
\text { - Well-controlled T1DM } \\
\text { - } \text { Well-controlled T2DM on MDI or } \\
\text { mixed insulin } \\
\text { - } \quad \text { Pregnant T2DM or GDM controlled by } \\
\text { - } \text { diet only or metformin } \\
\text { - SKD stage } 3 \\
\text { - } \quad \text { Patable macrovascular complications } \\
\text { - } \text { that present additional risk factors } \\
\text { People with diabetes performing } \\
\text { intense physical labour } \\
\text { - Treatment with drugs that may affect } \\
\text { cognitive function } \\
\text { Type } 2 \text { diabetes on SGLT-2 inhibitors } \\
\text { (consider alternatives/stopping) }\end{array}$ & \\
\hline $\begin{array}{l}\text { Category 3: moderate/low risk } \\
\text { Decision to not fast based on } \\
\text { discretion of medical opinion } \\
\text { and ability of the individual to } \\
\text { tolerate fast }\end{array}$ & $\begin{array}{l}\text { Well-controlled T2DM treated with one } \\
\text { or more of the following: } \\
\text { - Lifestyle therapy } \\
\text { - Metformin } \\
\text { - Acarbose } \\
\text { - Thiazolidinediones } \\
\text { - Second-generation SUs (moderate } \\
\text { risk, regular SMBG advised) } \\
\text { - Incretin-based therapy (DPP-4 } \\
\text { inhibitors or GLP-1 RAs) } \\
\text { - SGLT2 inhibitors } \\
\text { - Basal Insulin (moderate risk, regular } \\
\text { SMBG advised) }\end{array}$ & $\begin{array}{l}\text { Patients who fast should: } \\
\text { - } \text { Receive structured education } \\
\text { - Check their blood glucose } \\
\text { regularly (SMBG) } \\
\text { - } \text { Adjust medication dose as per } \\
\text { recommendations }\end{array}$ \\
\hline
\end{tabular}


Table 2 continued

Adapted IDF-DAR risk stratification table, reproduced with permission from the South East London Area Prescribing Committee [97]

$C K D$ Chronic kidney disease, $D K A$ diabetic ketoacidosis, DPP-4 dipeptidyl peptidase-4, GDM gestational diabetes mellitus, GLP-1 RA glucagon-like peptide-1 receptor agonist, $M D I$ multiple dose insulin, $M T F$ metformin, SGLT-2 sodium-glucose co-transporter 2, $S M B G$ self-monitoring of blood glucose, $S U$ sulfonylurea, TIDM Type 1 diabetes mellitus, T2DM Type 2 diabetes mellitus

${ }^{a}$ In all categories, people with diabetes should be advised to follow medical opinion due to probability of harm. The decision to fast is a personal decision for the person with diabetes, who should be supported by the healthcare professional (HCP) to achieve best possible outcomes

${ }^{\mathrm{b}}$ Hypoglycaemia that is not due to accidental error in insulin dose

c The expected level of glycaemic control is to be agreed upon between HCP and patient according to a multitude of factors. Glycated haemoglobin ( $\mathrm{HbAlc})>75 \mathrm{mmol} / \mathrm{mol}$ for $>12$ months should be used as an indicator of poor control

* Risk upgraded in light of COVID-19 pandemic

Ramadan-this can provide useful information to the patient to the patient as well as HCP team in arriving at a decision whether safe Ramadan fasting is achievable.

\section{Patient Education}

The CREED study showed that patients with T2 diabetes considered to be high risk or very high risk for fasting managed to fast successfully after having received structured education pre-Ramadan [48].

The Ramadan Education and Awareness in Diabetes (READ) study showed that pre-Ramadan education in patients with T2 diabetes was associated with greater weight loss and significant reduction in hypoglycaemic events [98]. Another study in T1 diabetes patients showed that adjustment of drug dosage, dietary advice, patient education and SMBG enabled patients to fast without major complications [76].

A study from Egypt looked at the benefit of diabetes self-management education in promoting safe fasting in Ramadan in people on insulin. This study included people attending Ramadan reinforcement sessions as part of the Educational Program for People with Diabetes (EPPWD) at the Ain-Shams University Diabetes Center in Cairo, Egypt. The number of hypoglycaemic events declined in these people, which advocates the use of education for fasting in patients with T2 diabetes [99].
The end of Ramadan is followed by the festival known as Eid ul-Fitr. This is usually marked with festivities, sharing of food and sweet beverages. Patients with diabetes should be advised on the risks of hyperglycaemia during this time, as many individuals overindulge in eating and drinking. When the month of Ramadan ends, the patient's therapeutic regimen should be adjusted and may be changed back to its previous regimen.

\section{Type 1 Diabetes: Education and Management}

Most of the recent data on T1 diabetes are from small observational studies and open-label interventional studies during Ramadan and consist of a mix of adult and paediatric studies. Larger observational data from the older EPIDIAR study has several limitations, as mentioned earlier [7]. Specifically in terms of T1 diabetes, the study was conducted in MENA and Asian countries during the mid-2000s; consequently, a large proportion of people with T1 diabetes enrolled in this study were on nonanalogue, biphasic insulin rather than intensive insulin therapy with insulin analogues. Also, a significant proportion of the people with $\mathrm{T} 1$ diabetes did not have regular HCP contact or support. What the EPIDIAR study did do was to highlight that pre-Ramadan optimization and education are needed and to point out the potential risks if these are not offered. Since its 
Table 3 Key aspects to cover during consultation

\begin{tabular}{|c|c|}
\hline Aspects & Advice \\
\hline SMBG & $\begin{array}{l}\text { - Importance and frequency of SMBG; identification, management and reporting of hypoglycaemia } \\
\text { and hyperglycaemia }\end{array}$ \\
\hline Diet & - Avoid foods of high glycaemic index; avoid indulgent eating \\
\hline $\begin{array}{l}\text { Fluids and meal } \\
\text { planning }\end{array}$ & $\begin{array}{l}\text { - In temperate countries where fasting is prolonged or when temperatures are hot, adequate non- } \\
\text { sugary fluid intake is advised }\end{array}$ \\
\hline Exercise & $\begin{array}{l}\text { - Regular light-to-moderate exercise is advised; it can be done anytime, but preferably a few hours } \\
\text { before Iftaar or just after a light Iftaar } \\
\text { - The special night prayer (Taraweeh), which can involve standing for prolonged periods, is a good } \\
\text { form of exercise for those who participate. This occurs within a congregation in the mosque and is } \\
\text { a form of exercise. Patients should keep treatment for hypoglycaemia }\end{array}$ \\
\hline Smoking & - Smoking invalidates a fast. Ramadan is an opportunity to promote smoking cessation \\
\hline Medication review & $\begin{array}{l}\text { - Optimization for Ramadan fasts with particular importance given to risk of hypoglycaemia, } \\
\text { duration of fasts and non-diabetes medication, such as diuretic usage }\end{array}$ \\
\hline $\begin{array}{l}\text { When to break the } \\
\text { fast }\end{array}$ & $\begin{array}{l}\text { - Blood glucose }<4 \mathrm{mmol} / \mathrm{L}(<5 \mathrm{mmol} / \mathrm{l} \text { if driving necessary) } \\
\text { - Blood glucose }>16.7 \mathrm{mmol} / \mathrm{L} \text { at any time during the fast (or pre-agreed threshold with HCP) } \\
\text { - Development of acute intercurrent illness causing significant physical, mental or physiological } \\
\text { compromise } \\
\text { - General deterioration in health causing significant physical, mental or physiological compromise }\end{array}$ \\
\hline Driving/travel & $\begin{array}{l}\text { - Determine if driving is required for work and/or social activities and further stratify patients } \\
\text { according to risk in relation to risk of harm when fasting } \\
\text { - If driving whilst fasting is going to occur, give relevant advice relating to hypoglycaemia that is } \\
\text { compatible with both secular and religious law }\end{array}$ \\
\hline Healthcre support & - A HCP should be identified for advice and support \\
\hline
\end{tabular}

HCP Healthcare professional, $S M B G$ Self-monitoring of blood glucose

publication there have been several major advances in $\mathrm{T} 1$ diabetes, including structured diabetes education programmes and new diabetes technologies, both of which allow safer and improved management of $\mathrm{T} 1$ diabetes [100]. Subsequent observational studies using these advances have highlighted the potential benefits in terms of improved glycaemic outcomes and safer fasting with reduced hypoglycaemia risk.

Regarding the general management of $\mathrm{T} 1$ diabetes, the Dose Adjustment for Normal Eating (DAFNE) programme, an educational course for managing $\mathrm{T} 1$ diabetes, has been shown to reduce severe hypoglycaemia and hyperglycaemia and improve the quality of life of participants [101, 102]. The importance of education is critical in being able to apply insulin therapy to challenging situations, such as exercise or shift work and dose adjusting in response to glucose data [103]. In terms of fasting, intensive education in children aged $>11$ years pre-Ramadan improved their ability to complete fasting [75]. Regular monitoring and dose adjustments have been shown to minimize hypoglycaemic events and DKA [72]. Other educational approaches specifically devised for Ramadan have demonstrated 
Table 4 A guide to dose adjustments for people taking antidiabetic agents who fast during Ramadan (Type 2 diabetes). Table is adapted and reproduced with permission from the South East London Area Prescribing Committee [97]

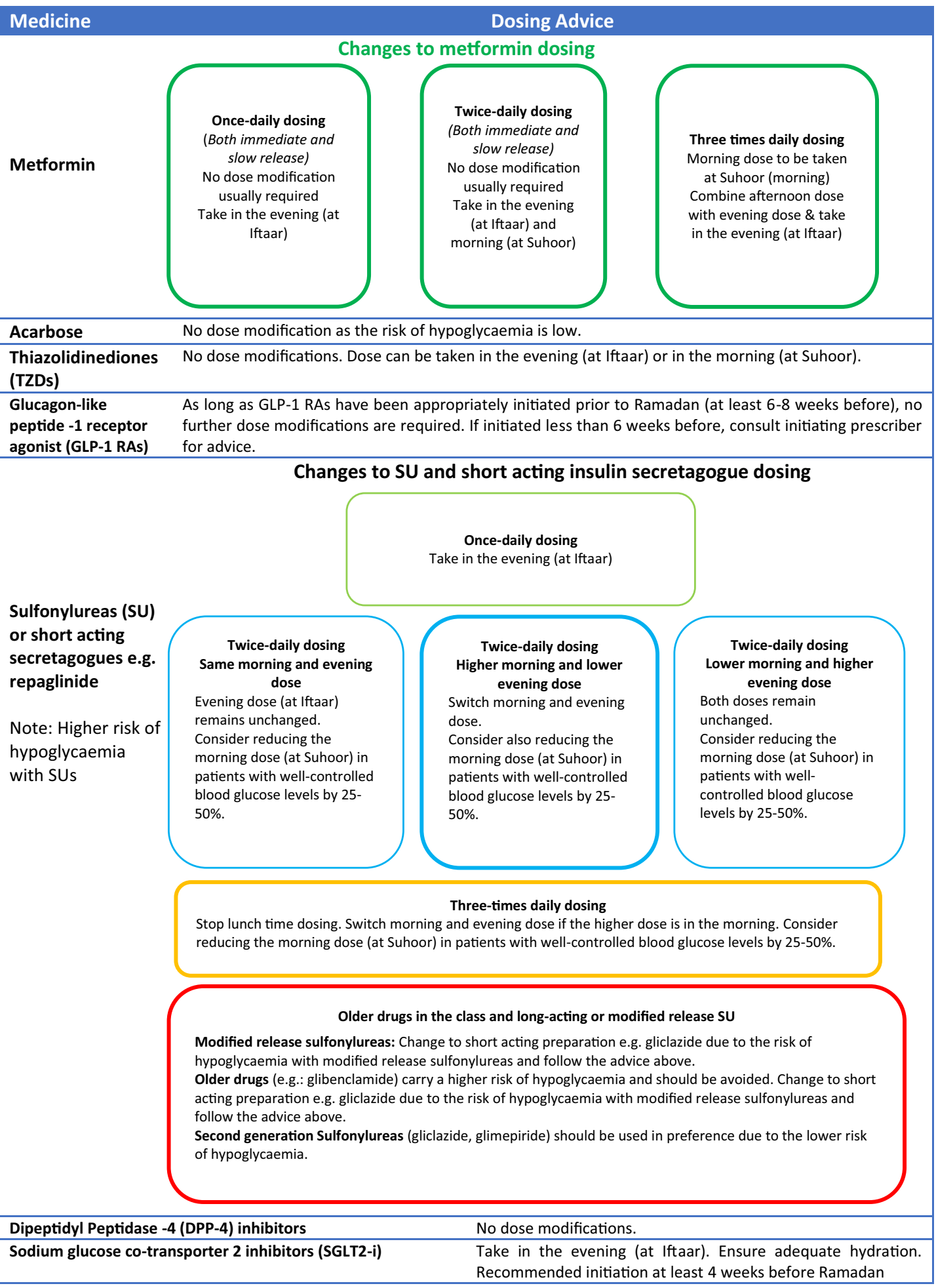


Table 5 A guide to dose adjustments for people with type 2 diabetes on insulin who fast during Ramadan

Insulin therapy

Basal therapy

Rapid- or short-acting prandial/bolus insulin

Biphasic insulin, e.g. 30/70, 25/75, 50/50 (high-risk group-winter fasting likely to be most practical and safest option when Ramadan in summer)

\section{Dosing advice}

- Once-daily dosing: to be administered in the evening (at Iftaar). Reduce dose by $15-30 \%$

- Twice-daily dosing: lower dose to be taken in the morning (at Suhoor). Reduce dose by $25-50 \%$. Higher dose to be taken in the evening (at Iftaar). No change to this dose

- Basal bolus dosing/basal plus: reduce basal dose by $15-30 \%$. Note: bolus as per usual strategy with meals e.g. not to be taken if the patient is not eating. Adjust bolus to intake

- Take normal dose in the evening (at Iftaar). Omit lunchtime dose. Reduce the morning dose (at Suhoor) by $25-50 \%$

- Once-daily dosing: take normal dose in the evening (at Iftaar)

- Twice-daily dosing (if equivalent doses in morning and evening): reduce morning dose by $50 \%$ and take in the morning (at Suhoor). Evening dose remains unchanged, take in the evening (at Iftaar). (Consider further reduction of morning dose if time between evening [Iftaar] and morning [Suhoor] meals is $<5 \mathrm{~h}$ )

- Twice-daily dosing (if higher dose in morning): switch the morning and evening dose. Consider reducing the switched dose in the morning (at Suhoor) by $50 \%$ if necessary. (Consider further reduction of morning dose if time between evening [Iftaar] and morning [Suhoor] meals is $<$ $5 \mathrm{~h}$ )

- Twice-daily dosing (if lower dose in morning): consider reducing morning dose by $50 \%$ if required and take in the morning (at Suhoor). Evening dose remains unchanged. Take at Iftaar. (Consider further reduction of morning dose if time between evening [Iftaar] and morning [Suhoor] meals is $<5 \mathrm{~h}$ )

- Three times daily dosing: omit lunchtime dose. Adjust morning dose and evening dose as described for twice-daily dosing above.

Table is adapted and reproduced with permission from the South East London Area Prescribing Committee [97] 
benefits [104]. Further studies, described in subsequent sections of this review, demonstrate the benefits of Ramadan-specific education comined with technology use.

With the newer analogue insulins the risks of hypoglycaemia are reduced and improved PPG levels can be achieved in T1 diabetes [105]. The use of these insulins needs to be coupled with education and frequent monitoring to achieve any benefits in glycaemic control. Evidence collected during Ramadan demonstrating the advantages of analogue insulins has been examined in several studies, mainly in the paediatric and adolescent settings [106]. The consensus of opinion, as reported in one of the larger studies, is that the utility of multiple daily injections and analogue insulin can offer improvements in hypoglycaemia and hyperglycaemia [107].

The use of technology has provided patients with T1 diabetes with further measures of safety during Ramadan. Continuous subcutaneous insulin infusion (CSII) via insulin pumps enables different levels of basal insulin delivery to be programmed and for smaller bolus doses, thereby allowing for flexibility in settings, such as for fasting, as well as small changes for those are insulin sensitive. A multicentre study comparing CSII with multiple dose insulin (MDI) and a recent systematic review comparing CSII with $\mathrm{MDI} /$ premixed insulin regimens have shown lower rates of severe hyperglycaemia/ hypoglycaemia and ketosis with CSII [108, 109], better glucose variability and better adherence to fasting [108]. Other studies have demonstrated that patients on CSII can safely fast during Ramadan if they have adequate pre-Ramadan education [110], with minimal adverse events such as hypoglycaemia or DKA $[83,111,112]$.

More recently, the widespread use of realtime glucose monitoring, in terms of both flash glucose monitoring and CGM, has offered further opportunities to reduce risks of fasting in patients with $\mathrm{T} 1$ diabetes by reducing fthe requency of hypoglycaemia and improving metabolic control. Coupled with education, real-time glucose monitoring can improve glycaemic control and hypoglycaemia frequency during Ramadan as compared to post-Ramadan $[101,113]$. There was a mild overall improvement in glycaemic outcomes during Ramadan as compared to post-Ramadan with flash glucose monitoring [74] and pre-Ramadan with CGM [101, 113]. The linking of CGM and CSII offers further opportunities to improve safety. Using the low-glucose suspend function in CSII systems further improves the safety of fasting in adolescents and young adults [114].

Hybrid-closed loop systems offer further potential to improve safety and improve glycaemic outcomes by linking CGM and CSII to deliver insulin in an automated manner via algorithms $[115,116]$. Initial experience with a commercially approved system demonstrates impressive glycaemic outcomes and parallels unpublished observations from open-source systems [116, 117].

Recent evidence and emerging data highlight the urgent need for updates in guidance on $\mathrm{T} 1$ diabetes and fasting given the advances in management [118]. Whilst attempts in general dose adjustments for insulin and CSII have been made [119], further work is needed to detail support strategies, education, dietary guidance and management in $\mathrm{T} 1$ diabetes similar to work done in other settings [103, 118].

\section{Pharmacological management}

\section{Metformin}

Metformin works by improving insulin sensitivity [120]. Therefore, the hypoglycaemia risk induced by metformin is very low. Although there are no studies that have observed the incidence of hypoglycaemia in those patients on metformin monotherapy and fasting, metformin is deemed safe to take during the month of Ramadan due to its low risk for hypoglycaemia [36].

The daily dose of metformin does not need to be altered, but some adjustments to the dosage interval are required for those on three times daily dosing. Such patients should take 
their lunchtime dose at Iftaar. Those on a prolonged-release formulation, which is usually taken once daily, should take their usual dose at Iftaar [45].

\section{Acarbose}

Acarbose inhibits the actions of alpha-glucosidase enzymes in the brush border of small intestines and pancreatic alpha-amylase, thus slowing down the absorption of glucose and modifying insulin secretion [121]. Like metformin, no dose adjustment of acarbose is needed during Ramadan as the risk of hypoglycaemia is low [36]. The combination of fasting-associated alteration in gut motility [122] and gut microbiota [123] can in theory, predispose a fasting individuals to the known gastrointestinal side-effects of acarbose. For patients who are prescribed acarbose three times daily, frequency can be reduced to twice daily coinciding with Suhoor and Iftaar. The dose taken with Suhoor can be reduced or even stopped during Ramadan, in view of the ensuing prolonged period of fasting.

\section{Thiazolidinediones}

Thiazolidinediones, such as pioglitazone, lower glucose by improving glucose uptake in peripheral tissues and by reducing insulin resistance [124]. Because of the low hypoglycaemia risk, thiazolidinediones are valuable agents to use during Ramadan [44]. It is worth noting that this class of drug should be initiated 10-12 weeks before Ramadan because of its slow maximal antihyperglycaemic effect [43].

To date, only study has researched the use of thiazolidinediones during Ramadan. This double-blind randomized controlled trial on pioglitazone found that when compared to placebo, the addition of pioglitazone to the patient's usual hypoglycaemic regimen did not increase the risk of hypoglycaemia. Pioglitazone also significantly improved glycaemic control during the early, mid- and post-Ramadan periods [125].
No dose adjustment of thiazolidinediones is required during Ramadan, and doses can be taken with Iftaar or Suhoor.

\section{Insulin Secretagogues}

Meglitinide Short-acting insulin secretagogues (IS), such as the meglitinides repaglinide and nateglinide, work by increasing insulin secretion through their stimulation of the pancreatic $\beta$ cells [126]. Studies examining the safety and efficacy of meglitinides and SUs for patients fasting during Ramadan are summarized in Table 6.

An observational study carried out in Turkey showed that there was no difference in the risk of hypoglycaemia when repaglinide, was compared to glimepiride and insulin glargine [55]. Another observational study demonstrated that there were no hypoglycaemic events when repaglinide was combined with insulin glargine [56], and similar results were seen by Anwar et al. [127], who compared repaglinide with glimepiride and found no difference in the incidence of hypoglycaemia between the two drugs.

Therefore, the short-acting duration of the meglitinides nateglinide and repaglinide make them favourable for use during Ramadan as they carry a low hypoglycaemia risk. As these agents are usually taken three times daily with main meals, their dosing will need to be adjusted during Ramadan to twice daily dosing so that they can be administered at Iftaar and Suhoor.

\section{Sulphonylureas}

Similar to the meglitinide class of oral antidiabetic agents, SUs stimulate insulin secretion from pancreatic $\beta$ cells [128]. However, their mechanism is glucose independent, resulting in a higher risk of hypoglycaemia and therefore making their use during Ramadan a concern.

The timing of taking SUs during Ramadan is key to their safety and efficacy. Although we advise changing patients on modified-release 
(MR) preparations to standard-release ones (Table 4), in those patients for whom this cannot be done for reasons such as patient preference or practicality of administration, switching the morning MR dose to the evening can be done safely without causing excessive hypoglycaemia [129]. A recently published real-world multinational observational study has shown that MR gliclazide between 60 and $90 \mathrm{mg}$ dose taken daily at Iftaar is associated with a low risk of hypoglycaemia and weight gain whilst maintaining control, in fasting patients with $\mathrm{HbA}_{1 \mathrm{c}}<9 \%$ [130]. Similarly, glimepiride was associated with fewer hypoglycaemic events when the morning dose was switched to the evening at Iftaar [131].

The duration of action of SUs taken during Ramadan should be considered. The use of glibenclamide has been shown to result in more hypoglycaemic events when compared to glimepiride, gliclazide [132] or repaglinide [133]. The use of older and longer-acting agents, such as glibenclamide, should be avoided during Ramadan and the patient switched to a shortacting SU or to repaglinide [55].

The newer generation of SUs, such as glipizide, glimepiride and gliclazide, are associatged with a lower risk of hypoglycaemia and are therefore safer to take during Ramadan [134]. We recommend that patients on gliclazide should halve the morning dose and take the usual dose in the evening as Iftaar tends to be the larger meal and characterized by a higher glycaemic index. Doses of gliclazide should be switched around if patients are taking a larger dose in the morning and a smaller dose in the evening. Glipizide that is taken once daily should be taken at Iftaar during Ramadan to minimize hypoglycaemia risk.

For those on combination therapy with longacting insulin, insulin and SU dose should be carefully titrated to minimize the risk of hypoglycaemia [135].

\section{Insulin}

Several studies have provided evidence for the use of insulin in patients with T2 diabetes who fast during Ramadan (Table 7). Rapid-acting insulin analogues, such as insulin lispro, have been shown to induce lower rates of hypoglycaemia than human insulin [136]. Long-acting insulins, such as insulin glargine, have been found to be safe as monotherapy [55] or in combination with an IS such as repaglinide [56]. However, for those on combination therapy consisting of insulin and an IS, dose titration is required to minimize the risk of hypoglycaemia [135].

Studies have also focussed on ensuring the safety and efficacy of pre-mixed insulins. In an observational study, premix insulin 30/70 (glargine or regular insulin) was found to be just as safe, in terms of hypoglycaemia, DKA or HHS, as long-acting insulin, provided the doses of insulin are reduced by $75 \%$ during pre-Ramadan assessment [80].

Soewondo et al. reported that use of biphasic insulin aspart was safe whilst fasting as there was a significant improvement in all glycaemic indices measured and a reduction in hypoglycaemic events compared to baseline, and no associated weight gain [137]. Other studies comparing premixed analogue insulins with human insulins have shown that premixed analogue insulins provide better average daily glucose control, especially around Iftaar time, without any increase in hypoglycaemia $[54,138]$. The combinations of long-acting and premixed insulins can be used to the advantage of the fasting individual by using pre-mixed insulin with the larger meal in the day, which is usually the Iftaar, and long-acting insulin with the smaller meal, which is generally Suhoor [139]. This approach can be tailored to the individual as this pattern of eating may vary among individuals.

Second-generation insulins may offer less glycaemic variability and hypoglycaemia and hence have a potential for use in Ramadan. The 
combination of insulin degludec/degludec and aspart insulin (IDegAsp) has been shown to be a safe and efficacious therapy during Ramadan $[64,140]$. In a recent real-world observational study, patients with $\mathrm{T} 2$ diabetes fasting in Ramadan who were taking insulin glargine 300 units/ml showed a low risk of severe/symptomatic hypoglycaemia and improved control [141].

The use of insulins, ranging from rapid-acting to long-acting analogues, ultra-long acting insulins and, pre-mix insulins, has been found to be safe and efficacious in Ramadan. Doses and timing should be adjusted in the pre-Ramadan assessment, and patients should be supported during Ramadan with dose titration in order to optimize their glycaemic control and thus their fasting experience.

\section{Dipeptidyl Peptidase-4 Inhibitors}

Dipeptidyl peptidase-4 inhibitor (DPP4i) drugs are oral hypoglycaemic agents that block the breakdown of endogenous GLP-1, which leads to the glucose-dependent release of insulin. They thus carry a low risk of hypoglycaemia, even when the patient is in the fasting state. Patients on DPP4i are considered to be a low risk for fasting, without a need for dose titration, and a number of trials have been conducted on the safety of this class of antihyperglycaemic agents administered with or without SU during Ramadan. Gray et al. performed a systematic review and meta-analysis of 16 studies conducted during Ramadan, ten of which compared DPP4i with a SU [65]. In this metaanalysis, one RCT did not show statistical difference in weight and $\mathrm{HbA}_{1 \mathrm{c}}$, and a second study did not show statistical difference in $\mathrm{HbA}_{1 \mathrm{c}}$. In two observational studies, sitagliptin significantly decreased the number of patients with $\geq 1$ hypoglycaemic events in Ramadan [66], and vildagliptin led to significant decreases in $\mathrm{HbA}_{1 \mathrm{c}}$ and weight versus a SU [67]. DPP4i led to fewer hypoglycaemic events compared to a SU.
Overall, studies conducted to date on the use of DPP4i in fasting T2D patients in Ramadan (Table 8) demonstrate a better tolerability and adherence, low rates of hypoglycaemia, better glycaemic control and potential less weight gain compared to a SU. Patients on DPP4i do not require treatment modifications during Ramadan.

\section{Glucagon-Like Peptide-1 Receptor Agonists}

Glucagon-like peptide-1 receptor agonists (GLP1 RA)s are drugs that mimic the function of endogenous incretin hormones and reduce blood glucose by glucose-dependent insulin release. They can also lead to reduced glucagon secretion and increased glucose uptake and can also delay gastric emptying and stimulate satiety centre by central effects [142]. GLP1 RAs are considered to represent as low risk for hypoglycaemia as monotherapy although in combination with SUs or insulin they may have the potential for hypoglycaemia [143].

Studies examining the safety and efficacy of GLP1 RAs for patients fasting during Ramadan are summarized in Table 9.

A large multinational open-labelled RCT (Lira-Ramadan) examined the effect of liraglutide $(n=171)$ compared to SU $(n=172)$ in T2 diabetes patients fasting in Ramadan and showed that no patient in either group experienced severe hypoglycaemia. Those in the liraglutide group had no major hypoglycaemic events and achieved a target $\mathrm{HBA}_{1 \mathrm{c}}$ of $<7.0 \%$, which was significantly better than those in the SU group (53.9 vs. 23.5\%; $p<0.001$ ) [68].

An RCT in the UK that compared liraglutide as monotherapy or in combination with metformin $(n=47)$ with SU $(n=52)$, showed no severe hypoglycaemia in both groups and significantly lower self-reported episodes of hypoglycaemia $(\leq 3.9 \mathrm{mmol} / \mathrm{L})$ in the liraglutide group. Further analysis 12 weeks after Ramadan showed a significant reduction in $\mathrm{HbA}_{1 \mathrm{c}}$, weight and diastolic blood pressure in those patients on liraglutide [69]. 
The authors of an observational study examining the safety and efficacy of liraglutide [59] and those of an open-label parallel-group clinical trial comparing lixisenatide with SU [70] concluded that both drugs were safe and led to a reduced frequency of hypoglycaemia in Ramadan.

Given the safety and efficacy of GLP-1 analogues demonstrated by these studies (Table 9), during Ramadan fasting, we recommend that members of this class of medications be considered as options for second-line agents to optimize diabetes control.

\section{Sodium-Glucose Cotransporter-2 Inhibitors}

Sodium-glucose cotransporter-2 inhibitors (SGLT-2i)s work by reducing the reabsorption of glucose through the proximal convoluted tubules of the kidneys by inhibiting the SGLT-2 receptors [144], a mechanism which can in turn lead to caloric loss with a reduction in $\mathrm{HbA}_{1 \mathrm{c}}$ as well as weight loss. There is, however, a potential for an increased risk of dehydration with the use of these medications, although recent studies have shown that this risk is not high in temperate climates [145].

Due to potential concerns regarding volume loss, dehydration and postural hypotension, Muslim doctors in the Middle East were surveyed; all of those surveyed had substantial experience with patients who fast for Ramadan. Analysis of the results revealed that most respondants felt safe prescribing SGLT-2is during Ramadan [146].

Studies examining the safety and efficacy of these medications for patients fasting during Ramadan are summarized in Table 10. The first study to be carried out, by Wan Seman et al. [71], compared the use of the SGLT-2i dapagliflozin with SU in 110 patients in Malaysia with T2 diabetes. This was an open-label study that showed a significantly reduced frequency of hypoglycaemia in the SGLT-2i arm versus the SU arm. In terms of adverse events there was non-significant increased risk of urinary tract infection and postural hypotension in patients in the the SGLT-2i arm compared to patients in the sulphonylurea arm. There was no report of DKA [71].

Another non-randomized parallel-cohort, prospective observational study enrolled patients taking canagliflozin $(n=162)$ or any $\mathrm{SU}(n=159)$ added to metformin \pm DPP4i [60]. There was a near-significant $(p=0.09)$ reduction in the frequency of hypoglycaemia in the SGLT-2i arm versus the SU arm. However, there was a non-significant increased reporting of at least one volume depletion event in the SGLT-2i arm (9 vs. $3.8 \%)$.

Finally, a small single-centre prospective observational controlled cohort study in Singapore examining the effect of effect of SGLT-2i use on ketonaemia, blood pressure and renal function in T2 diabetes patients $(n=68)$ during Ramadan showed neither an increase in ketonaemia nor an increase in deterioration of estimated glomerular filtration rate (eGFR) and hypoglycaemia. Both groups had a similar change in weight, eGFR, sitting systolic, sitting diastolic blood pressure and plasma $\beta-\mathrm{OHB}$ level. The proportion of patients experiencing at least one hypoglycaemic event during fasting non-significantly increased in the control group and decreased in the study group [63].

Despite some concerns, studies have actually demonstrated that SGLT-2i remain a safe class of drugs during the fasting month of Ramadan. However, we would advise the usual caveats of patients being aware of sick day rules and ensuring that they are properly hydrated to minimize the risks of these drugs. 
Table 6 Summary of evidence on the safety and efficacy of meglitinides and sulfonylureas during Ramadan

\begin{tabular}{|c|c|c|c|}
\hline $\begin{array}{l}\text { First author } \\
\text { of study/ } \\
\text { publication } \\
\text { year }\end{array}$ & Intervention & Characteristics & Outcomes \\
\hline $\begin{array}{c}\text { Cesur/2007 } \\
{[55]}\end{array}$ & $\begin{array}{l}\text { Comparison of glargine, repaglinide } \\
\text { and glimepiride on } \mathrm{HbA}_{1 \mathrm{c}}, \mathrm{FBG}, \\
\text { postprandial blood glucose, } \\
\text { fructosamine and lipid levels and } \\
\text { risk of hypoglycaemia. }\end{array}$ & $\begin{array}{l}\text { Observational, single site, } \\
\text { Turkey. } \\
N=49 \text {; fasting } \\
N=16 \text {; control (non- } \\
\text { fasting) }\end{array}$ & $\begin{array}{l}\text { - No differences in } \mathrm{HbA}_{\mathrm{lc}} \text { and } \\
\text { fructosamine amongst the three } \\
\text { drug groups, but prandial blood } \\
\text { glucose was higher in the control } \\
\text { group post-Ramadan and 1-month } \\
\text { post-Ramadan ( } p<0.05 \text { and } \\
p<0.001 \text {, respectively). } \\
\text { - High fructosamine levels in both } \\
\text { control and fasting group. } \\
\text { - Risk of hypoglycaemia did not differ } \\
\text { between the drug groups } \\
\text { - No changes in lipid profile noted in } \\
\text { fasting diabetics }\end{array}$ \\
\hline $\begin{array}{c}\text { Salti/2009 } \\
\text { [135] }\end{array}$ & $\begin{array}{l}\text { Comparison of incidence of } \\
\text { hypoglycaemia when glargine is } \\
\text { combined with glimepiride }\end{array}$ & $\begin{array}{l}\text { Open, descriptive, } \\
\text { multicentre, prospective } \\
\text { study } \\
N=349: \text { insulin-naive } \\
\quad(n=100) \text { or previously } \\
\text { insulin-treated }(n=249)\end{array}$ & $\begin{array}{l}\text { - Only one episode of severe } \\
\text { hypoglycaemia occurred in each } \\
\text { time period before, during and after } \\
\text { Ramadan. } \\
\text { Mild hypoglycaemic episodes } \\
\text { increased from } 156 \text { pre-Ramadan to } \\
346 \text { during Ramadan }(p<0.001) \\
\text { and decreased to } 153 \text { post-Ramadan } \\
\text { ( } p=0.0002) \\
\text { - FBG and } \mathrm{HbA}_{1 \mathrm{c}} \text { improved during } \\
\text { the titration period and did not } \\
\text { change during the rest of the study }\end{array}$ \\
\hline $\begin{array}{l}\text { Bakiner/ } \\
2009 \text { [56] }\end{array}$ & $\begin{array}{l}\text { Comparison of incidence of } \\
\text { hypoglycaemia when glargine is } \\
\text { combined with repaglinide }\end{array}$ & $\begin{array}{l}N=7 \text {; fasting } \\
N=7 ; \text { control (non- } \\
\text { fasting) }\end{array}$ & $\begin{array}{l}\text { - No hypoglycaemic events recorded } \\
\text { in both groups } \\
\text { - No changes in } \mathrm{HbA}_{1 \mathrm{c}} \text { and } \\
\text { fructosamine were observed in both } \\
\text { groups }\end{array}$ \\
\hline
\end{tabular}


Table 6 continued

\begin{tabular}{|c|c|c|c|}
\hline $\begin{array}{l}\text { First author } \\
\text { of study/ } \\
\text { publication } \\
\text { year }\end{array}$ & Intervention & Characteristics & Outcomes \\
\hline $\begin{array}{l}\text { Zargar/ } \\
2010 \\
{[129]}\end{array}$ & $\begin{array}{l}\text { Evaluating the effect on incidence of } \\
\text { hypoglycaemia when modified- } \\
\text { release gliclazide } 60 \mathrm{mg} \text { is switched } \\
\text { from morning administration to } \\
\text { evening during Ramadan }\end{array}$ & $\begin{array}{l}\text { Observational, multi- } \\
\text { country study involving } \\
\text { Bangladesh, India and } \\
\text { Pakistan } \\
N=136 \text {; all males }\end{array}$ & $\begin{array}{l}\text { - FBG decreased by } 0.01 \mathrm{mmol} / \mathrm{L} \\
(95 \% \text { CI } 0-0.2 ; p=0.3) \text { with } \\
\text { evening medication by the end of } \\
\text { Ramadan and increased by } \\
0.2 \mathrm{mmol} / \mathrm{L}(95 \% \text { CI } 0.1-0.3 ; \\
p=0.01) \text { ] after reverting to } \\
\text { morning medication } \\
\text { - There were } 5(3.7 \%) \text { hypoglycaemic } \\
\text { episodes before, } 3(2.2 \%) \text { during and } \\
2(1.5 \%) \text { after Ramadan }\end{array}$ \\
\hline $\begin{array}{l}\text { Aravind/ } \\
2011 \\
{[132]}\end{array}$ & $\begin{array}{l}\text { Comparison of glibenclamide, } \\
\text { gliclazide, and glimepiride } \pm \text { MTF } \\
\text { on incidence of hypoglycaemia }\end{array}$ & $\begin{array}{l}\text { Observational, multisite } \\
\text { study } \\
N=1378\end{array}$ & $\begin{array}{l}\text { - } 19.7 \% \text { of the participants } \\
\text { experienced } \geq 1 \text { symptomatic } \\
\text { hypoglycaemic event during } \\
\text { Ramadan, with incidences of } 25.6, \\
16.8 \text { and } 14.0 \% \text { observed in subjects } \\
\text { treated with glibenclamide, } \\
\text { glimepiride and gliclazide, } \\
\text { respectively } \\
\text { - The overall incidence of severe } \\
\text { hypoglycaemic events was } 6.7 \%, \\
\text { with the highest incidence occurring } \\
\text { in the glibenclamide group }\end{array}$ \\
\hline $\begin{array}{l}\text { Mafauzy/ } \\
2002 \\
{[133]}\end{array}$ & $\begin{array}{l}\text { Comparison of repaglinide and } \\
\text { glibenclamide on } \mathrm{HbA}_{1 c} \text {, } \\
\text { fructosamine levels and incidence of } \\
\text { hypoglycaemia. }\end{array}$ & $\begin{array}{l}\text { Observational study } \\
N=255\end{array}$ & $\begin{array}{l}\text { - The number of hypoglycaemia } \\
\text { events was significantly lower in the } \\
\text { repaglinide group }(2.8 \%) \text { than in } \\
\text { the glibenclamide group }(7.9 \%) \\
(p=0.001) \text {. } \\
\text { - Fructosamine levels were } \\
\text { significantly reduced in the } \\
\text { repaglinide group }(p<0.05) \text {, but } \\
\text { this was not seen with glibenclamide } \\
\text { group } \\
\text { - There was no significant difference } \\
\text { in } \mathrm{HbA}_{1 \mathrm{c}} \text { between the two groups }\end{array}$ \\
\hline
\end{tabular}


Table 6 continued

\begin{tabular}{|c|c|c|c|}
\hline $\begin{array}{l}\text { First author } \\
\text { of study/ } \\
\text { publication } \\
\text { year }\end{array}$ & Intervention & Characteristics & Outcomes \\
\hline $\begin{array}{l}\text { GLIRA } \\
\text { study } \\
\text { group/ } \\
2005 \\
{[131]}\end{array}$ & $\begin{array}{l}\text { Evaluating the effect on incidence of } \\
\text { hypoglycaemia when glimepiride is } \\
\text { switched from morning } \\
\text { administration to evening during } \\
\text { Ramadan }\end{array}$ & $\begin{array}{l}\text { Open-label, prospective, } \\
\text { observational study } \\
\text { carried out in } 33 \text { centres } \\
\text { in } 6 \text { countries } \\
N=323 \text {; glimepiride }\end{array}$ & $\begin{array}{l}\text { - The incidence of hypoglycaemia } \\
\text { during Ramadan was similar to that } \\
\text { in pre- and post-Ramadan: } 3 \% \text { in } \\
\text { newly diagnosed patients and } 3.7 \% \\
\text { in previously treated patients }\end{array}$ \\
\hline $\begin{array}{c}\text { Anwar/2005 } \\
{[127]}\end{array}$ & $\begin{array}{l}\text { Comparison of repaglinide and } \\
\text { glimepiride on } \mathrm{HbA}_{1 \mathrm{c}} \text { and } \\
\text { incidence of hypoglycaemia }\end{array}$ & $\begin{array}{l}\text { Observational study } \\
N=41 ; \mathrm{SU} \pm \text { MTF and } \\
\text { repaglinide }(n=20) \text { or } \\
\text { SU } \pm \text { SU and } \\
\text { glimepiride }(n=21)\end{array}$ & $\begin{array}{l}\text { - Those participants on triple doses } \\
\text { of repaglinide were redistributed to } \\
\text { two pre-prandial doses } \\
\text { - Blood glucose was significantly } \\
\text { lower in the glimepiride group than } \\
\text { in the repaglinide group both during } \\
\text { and after Ramadan } \\
\text { - There was no statistically significant } \\
\text { difference in the incidence of } \\
\text { hypoglycaemia between the two } \\
\text { groups during and after Ramadan }\end{array}$ \\
\hline
\end{tabular}

$C I$ Confidence interval, $F B G$ fasting blood glucose 
Table 7 Summary of evidence for the use of insulins during Ramadan

\begin{tabular}{|c|c|c|c|}
\hline $\begin{array}{l}\text { First author } \\
\text { of study/ } \\
\text { publication } \\
\text { year }\end{array}$ & Intervention & Characteristics & Outcomes \\
\hline $\begin{array}{l}\text { Akram/1999 } \\
{[136]}\end{array}$ & $\begin{array}{l}\text { Comparison of insulin lispro } \\
\text { with soluble human insulin }\end{array}$ & $\begin{array}{l}\text { Open-label, randomized } \\
\text { cross-over study } \\
N=70\end{array}$ & $\begin{array}{l}\text { Hypoglycaemic events: } \\
\text { - Inulin lispro } 1.3 \pm 0.1 \text { vs. soluble } \\
\text { insulin } 2.6 \pm 0.2(p<0.002)\end{array}$ \\
\hline $\begin{array}{l}\text { Mattoo/2003 } \\
\quad[54]\end{array}$ & $\begin{array}{l}\text { Comparison of insulin lispro } \\
\text { mix } 25 \text { with human insulin } \\
30 / 70\end{array}$ & $\begin{array}{l}\text { Open-label, multicentre, } \\
\text { randomized, cross-over } \\
\text { study } \\
N=151\end{array}$ & $\begin{array}{l}\text { - Average daily blood glucose: insulin } \\
\text { lispro mix } 259.5 \pm 2.4 \text { vs. human } \\
\text { insulin } 30 / 7010.1 \pm 2.5(p=0.004) \\
\text { - 2-h PPG: insulin lispro mix } 25 \\
3.4 \pm 2.9 \mathrm{mmol} / 1 \text { vs. human insulin } \\
30 / 704.0 \pm 3.2(p=0.001) \\
\text { - Pre-meal FBG lispro mix } 25 \\
7.1 \pm 2.2 \mathrm{mmol} / 1 \text { vs. human insulin } \\
30 / 707.5 \pm 2.6 \mathrm{mmol} / \mathrm{l}(p=0.034)\end{array}$ \\
\hline $\begin{array}{l}\text { Cesur/2007 } \\
\text { [55] }\end{array}$ & $\begin{array}{l}\text { Comparison of glimepiride, } \\
\text { repaglinide and glargine } \\
\text { Non-fasting control group }\end{array}$ & $\begin{array}{l}\text { Observational study } \\
N=65\end{array}$ & $\begin{array}{l}\text { - No significant change from pre- } \\
\text { Ramadan FBG, PPG and } \mathrm{HbA}_{1 \mathrm{c}} \\
\text { - No significant difference in } \\
\text { hypoglycaemic events between fasting } \\
\text { and non-fasting groups }\end{array}$ \\
\hline $\begin{array}{l}\text { Bakiner/2009 } \\
\quad[56]\end{array}$ & Repaglinide + glargine & $\begin{array}{l}\text { Observational study } \\
N=14\end{array}$ & $\begin{array}{l}\text { - Glucose control remained unchanged } \\
\text { between groups } \\
\text { - No hypoglycaemic events noted }\end{array}$ \\
\hline $\begin{array}{l}\text { Salti/2009 } \\
\quad[135]\end{array}$ & $\begin{array}{l}\text { Effects of use of glargine and } \\
\text { glimepiride during Ramadan } \\
\text { fasting }\end{array}$ & $\begin{array}{l}\text { Open, descriptive, } \\
\text { multicentre, prospective } \\
\text { study } \\
N=359\end{array}$ & $\begin{array}{l}\text { - Mild hypoglycaemic episodes increased } \\
\text { from } 156 \text { pre-Ramadan to } 346 \text { during } \\
\text { Ramadan }(p<0.001) \text { and decreased to } \\
153 \text { post-Ramadan }(p=0.0002) \text {. }\end{array}$ \\
\hline $\begin{array}{l}\text { Hassanein/ } \\
2018[64]\end{array}$ & $\begin{array}{l}\text { Comparison of IDeg/Aspart } \\
\text { versus biphasic insulin aspart } \\
30\end{array}$ & $\begin{array}{l}\text { Phase } 3 \text {, multicenter, } \\
\text { international, open-label, } \\
\text { randomized, treat-to- } \\
\text { target trial } \\
N=263\end{array}$ & $\begin{array}{l}\text { - IDegAsp group significantly lower } \\
\text { overall/nocturnal hypoglycaemia rates } \\
\text { with similar glycaemic efficacy compared } \\
\text { to BIAsp30 } \\
\text { - IDegAsp did show a significantly lower } \\
\text { pre-Iftaar SMBG }\end{array}$ \\
\hline $\begin{array}{l}\text { Kalra/2016 } \\
\qquad[140]\end{array}$ & $\begin{array}{l}\text { Patients switched from } \\
\text { premixed and NPH to } \\
\text { IDegAsp or IDeg }\end{array}$ & $\begin{array}{l}\text { Real-world observational } \\
\quad \text { study } \\
N=6\end{array}$ & $\begin{array}{l}\text { - No severe hypoglycemia } \\
\text { - } 3 \text { patients had } 11 \text { episodes of } \\
\text { symptomatic hypoglycaemia }\end{array}$ \\
\hline
\end{tabular}


Table 7 continued

\begin{tabular}{|c|c|c|c|}
\hline $\begin{array}{l}\text { First author } \\
\text { of study/ } \\
\text { publication } \\
\text { year }\end{array}$ & Intervention & Characteristics & Outcomes \\
\hline $\begin{array}{l}\text { Soewondo/ } \\
2009[137]\end{array}$ & $\begin{array}{l}\text { Biphasic insulin aspart as } \\
\text { monotherapy or in } \\
\text { combination with oral } \\
\text { hypoglycaemic agent }\end{array}$ & $\begin{array}{l}\text { Multicentre prospective } \\
\text { non-interventional study } \\
N=152\end{array}$ & $\begin{array}{l}\text { - Hypoglycaemic event reduced compared } \\
\text { to baseline } \\
\text { - Fasting plasma glucose, 2-h PPG and } \\
\mathrm{HbA}_{1 \mathrm{c}} \text { all improved significantly } \\
\text { - No increase in weight }\end{array}$ \\
\hline $\begin{array}{c}\mathrm{Hui} / 2010 \\
{[138]}\end{array}$ & $\begin{array}{l}\text { Comparison of Humalog mix } \\
50 \text { with human insulin mix } \\
30\end{array}$ & $\begin{array}{l}\text { Observational study } \\
\text { Group 1: Humalog mix } 50 \\
\text { and human insulin mix } \\
30 \\
\text { Group 2: Human insulin } \\
\text { mix } 30 \text { twice daily } \\
N=52\end{array}$ & $\begin{array}{l}\mathrm{HbA}_{\mathrm{lc}} \Delta \text { : } \\
\text { - Group } 1 \text { reduction by } 0.48 \% \\
\text { ( } p=0.0001) \text { before and after Ramadan. } \\
\text { - Group } 2 \text { increased by } 0.28 \%(p=0.007) \\
\text { during Ramadan } \\
\text { - Mean number of hypoglycaemic events } \\
\text { during Ramadan } \\
\text { - Group } 1 \text { reduction of } 0.04 \text { ( } p=0.81 \text { ) } \\
\text { - Group } 2 \text { increase of } 0.15 \text { ( } p=0.43) \\
\text { - These differences between the groups } \\
\text { were not statistically significant following } \\
\text { adjustment for baseline factors (least } \\
\text { squares mean difference between } \\
\text { groups }=0.135, p=0.36,95 \% \text { CI } \\
\text { - } 0.16 \text { to } 0.43 \text { ) }\end{array}$ \\
\hline $\begin{array}{l}\text { Shehadeh/ } \\
2015 \text { [139] }\end{array}$ & $\begin{array}{l}\text { Insulin detemir at Suhoor and } \\
\text { premixed insulin at Iftaar. } \\
\text { Control group was standard } \\
\text { care }\end{array}$ & $\begin{array}{l}\text { Open-label, controlled, } \\
\text { randomized, non- } \\
\text { inferiority study } \\
N=238\end{array}$ & $\begin{array}{l}\text { - Intervention arm was non-inferior to } \\
\text { standard care arm } \\
\text { - Mean 4P-SMBG during days } 23-30 \text { of } \\
\text { treatment }(155 \text { [SD 30.76] mg } \% \text { and } \\
159 \text { [SD 33.24] mg \%, respectively, } \\
p=0.269] \\
\text { - Hypoglycaemia event rate was lower in } \\
\text { the intervention group (0.00 [SD 0.01] } \\
\text { vs. } 0.01 \text { [SD 0.03], } p \leq 0.001)\end{array}$ \\
\hline
\end{tabular}

BIAsp30 Biphasic insulin aspart 30/70, IDeg Insulin degludec, IDeg/Aspart co-formulation insulin degludec/insulin aspart, $N P H$ neutral protamine hagedorn (insulin), $P P G$ postrandial glucose, $S D$ standard deviation, $4 P$ 4-point $\Delta$ change 
Table 8 Summary of evidence for the use of dipeptidyl peptidase-4 inhibitors during Ramadan

\begin{tabular}{|c|c|c|c|}
\hline $\begin{array}{l}\text { First author } \\
\text { of study/ } \\
\text { publication } \\
\text { year }\end{array}$ & Intervention & Characteristics & Outcomes \\
\hline $\begin{array}{l}\text { Devendra/ } \\
2009[161]\end{array}$ & $\begin{array}{l}\text { Comparison of hypoglycaemic events, } \\
\mathrm{HbA}_{1 \mathrm{c}} \text {, bodyweight changes with } \\
\text { vildagliptin and gliclazide as add-on to } \\
\text { MTF }\end{array}$ & $\begin{array}{l}\text { Observational } \\
\text { prospective cohort } \\
\text { study } \\
N=52\end{array}$ & $\begin{array}{l}\text { Hypoglycaemia incidence } \\
\quad(\mathrm{BG}<3.5 \mathrm{mmol} / \mathrm{L}): \\
\text { - Vildagliptin } 7.7 \% \text {; gliclazide } 61.5 \% \\
\quad(p<0.001) \\
\text { Body weight } \Delta: \\
\text { - Vildagliptin: }+0.34 \mathrm{~kg} ; \mathrm{SU}: \\
+0.8 \mathrm{~kg}(p<0.001) \\
\text { HbA }_{1 \mathrm{c}} \Delta \text { : } \\
\text { - Vildagliptin }-1.26 \% \text {; SU } \\
-1.23 \%(p=0.8217)\end{array}$ \\
\hline $\begin{array}{l}\text { Hassanein/ } \\
2011 \text { [67] }\end{array}$ & $\begin{array}{l}\text { Comparison of incidence of } \\
\text { hypoglycaemia events between } \\
\text { vildagliptin and SU; MTF in both arms }\end{array}$ & $\begin{array}{l}\text { Double-blinded RCT } \\
N=59\end{array}$ & $\begin{array}{l}\text { - No hypoglycaemia with } \\
\text { vildagliptin } \\
\text { - } 34 \text { hypoglycaemic events }(15 \\
\text { patients, } 41.7 \%) \text { including } 1 \text { severe } \\
\text { with } S U \\
\text { - Mean } \mathrm{HBA}_{1 \mathrm{c}} \text { difference between } \\
\text { groups: }-0.5 \%(p=0.0262)\end{array}$ \\
\hline $\begin{array}{c}\text { Sifri/2011 } \\
{[162]}\end{array}$ & $\begin{array}{l}\text { Comparison of incidence of symptomatic } \\
\text { hypoglycaemia between sitagliptin and } \\
\text { SU }\end{array}$ & $\begin{array}{l}\text { Prospective RCT } \\
N=1021\end{array}$ & $\begin{array}{l}\text { Hypoglycaemia incidence: } \\
-6.7 \% \text { with sitagliptin vs. } 13.2 \% \\
\text { with SU }(p<0.001)\end{array}$ \\
\hline $\begin{array}{l}\text { Aravind } / 2012 \\
{[66]}\end{array}$ & $\begin{array}{l}\text { Comparison of incidence of symptomatic } \\
\text { hypoglycaemia between sitagliptin and } \\
\text { SU }\end{array}$ & $\begin{array}{l}\text { Prospective RCT } \\
N=848\end{array}$ & $\begin{array}{l}\text { Hypoglycaemia incidence: } \\
-3.8 \% \text { with sitagliptin vs. } 7 / 3 \% \text { with } \\
\text { SU }\end{array}$ \\
\hline $\begin{array}{l}\text { Halimi/2013 } \\
{[163]}\end{array}$ & $\begin{array}{l}\text { Real-world study assessing rate of } \\
\text { hypoglycaemia with vildagliptin-treated } \\
\text { patients vs. IS }\end{array}$ & $\begin{array}{l}\text { Prospective, non- } \\
\quad \text { interventional study } \\
N=218\end{array}$ & $\begin{array}{l}\text { Percentage patients with severe } \\
\text { hypoglycaemia and/or an } \\
\text { unscheduled medical visit due to } \\
\text { hypoglycaemia: } \\
\text { - IS vs. vildagliptin (10.4 vs. } 2.6 \% \text {, } \\
\text { respectively; } p=0.029) \text {. } \\
\text { Percentage patients who had } \\
\text { missed } \geq 5 \text { doses lower in the } \\
\text { vildagliptin }(8.5 \%) \text { vs. IS }(15.4 \%) \\
\text { group }\end{array}$ \\
\hline
\end{tabular}


Table 8 continued

\begin{tabular}{|c|c|c|c|}
\hline $\begin{array}{l}\text { First author } \\
\text { of study/ } \\
\text { publication } \\
\text { year }\end{array}$ & Intervention & Characteristics & Outcomes \\
\hline $\begin{array}{l}\text { Shete/2013 } \\
\quad[164]\end{array}$ & $\begin{array}{l}\text { Comparison of effects of vildagliptin and } \\
\text { SU with or without MTF }\end{array}$ & $\begin{array}{l}\text { Non-interventional, } \\
\text { open-label, } \\
\text { observational study } \\
N=97\end{array}$ & $\begin{array}{l}\text { Hypoglycaemia incidence: } \\
\text { - Vildagliptin } 0 ; \mathrm{SU} 4.8 \% \\
\text { - } \mathrm{HbA}_{1 \mathrm{c}} \Delta \text { : } \\
\text { - Vildagliptin }-0.43 \%: \mathrm{SU}+0.01 \% \\
\quad(p=0.009) \\
\text { Body weight } \Delta \text { : } \\
\text { - Vildagliptin }-1.2 \mathrm{~kg} ; \mathrm{SU} 0.03 \mathrm{~kg} \\
(p<0.001)\end{array}$ \\
\hline $\begin{array}{l}\text { Al-Arouj/ } \\
2013[165]\end{array}$ & $\begin{array}{l}\text { Real-world study assessing the effect of } \\
\text { vildagliptin compared to SU }\end{array}$ & $\begin{array}{l}\text { Non-interventional } \\
\text { observational study } \\
N=1315\end{array}$ & $\begin{array}{l}\text { Hypoglycaemic events: } \\
\text { - Vildagliptin vs. SU: } 5.4 \text { vs. } 19.8 \% \text {, } \\
\text { respectively }(p<0.001) \\
\mathrm{HbA}_{1 \mathrm{c}} \Delta \text { : } \\
\text { - Vildagliptin }-0.24 \%, \mathrm{SU}+0.02 \% \\
(p<0.001) \\
\text { Body weight } \Delta \text { : } \\
\text { - Vildagliptin }-0.76 \mathrm{~kg}, \mathrm{SU} \\
-0.13 \mathrm{~kg}(p<0.001)\end{array}$ \\
\hline $\begin{array}{l}\text { Malha/2014 } \\
\quad[166]\end{array}$ & $\begin{array}{l}\text { Comparison of hypoglycaemic events, } \\
\mathrm{HbA}_{1 \mathrm{c}} \text {, bodyweight changes in patients } \\
\text { on vildagliptin }+ \text { MTF and } \\
\text { gliclazide }+ \text { MTF }\end{array}$ & $\begin{array}{l}\text { Randomized, open- } \\
\text { label, trial } \\
N=69\end{array}$ & $\begin{array}{l}\text { Hypoglycaemia incidence: } \\
\text { - Vildagliptin 19\%; gliclazide 26\% } \\
(p=0.334) \\
\mathrm{HbA}_{1 \mathrm{c}} \Delta \text { : } \\
\text { - Vildagliptin }-0.83 \% \text {; gliclazide } \\
0.96 \% \\
\text { BMI } \Delta \text { : } \\
\text { - Vildagliptin }-0.7 \mathrm{~kg} / \mathrm{m}^{2} ; \mathrm{SU} \\
+0.9 \mathrm{~kg} / \mathrm{m}^{2}\end{array}$ \\
\hline $\begin{array}{l}\text { Hassanein/ } \\
2014[58]\end{array}$ & $\begin{array}{l}\text { Comparison of incidence of } \\
\text { hypoglycaemia events between } \\
\text { vildagliptin and } \mathrm{SU}\end{array}$ & $\begin{array}{l}\text { Prospective cohort } \\
\text { double-blinded } \\
\text { randomized } \\
\text { observational study } \\
N=557\end{array}$ & $\begin{array}{l}\text { Hypoglycaemia }(<3.9 \mathrm{mmol} / \\
\mathrm{L} \pm \text { severe }): \\
\text { - Vildagliptin } 3.0 \% \text { vs Gliclazide } \\
7.0 \%, p=0.039\end{array}$ \\
\hline
\end{tabular}

IS Insulin secretagogues, $R C T$ randomized controlled trial 
Table 9 Summary of evidence for the use of glucagon-like peptide-1 receptor agonists during Ramadan

\begin{tabular}{|c|c|c|c|}
\hline $\begin{array}{l}\text { First author of } \\
\text { study/publication } \\
\text { year }\end{array}$ & Intervention & Characteristics & Outcomes \\
\hline Azar/2015 [68] & $\begin{array}{l}\text { Comparison of liraglutide } 1.8 \mathrm{mg} \text { and } \\
\text { SU; MTF in both arms }\end{array}$ & $\begin{array}{l}\text { Open-label, randomized, } \\
\text { active-controlled, parallel- } \\
\text { group trial } \\
N=341\end{array}$ & $\begin{array}{l}\mathrm{HbA}_{1 \mathrm{c}} \Delta: \\
\text { - Liraglutide }(-0.59 \%) \text { vs. SU } \\
\quad(-0.38 \%), p<0.0001 \\
\text { Weight } \Delta: \\
\text { - Liraglutide }>\mathrm{SU} \text { (by } \\
\quad-0.54 \mathrm{~kg}), p=0.0091 \\
\text { Hypoglycaemia: } \\
\text { - Liraglutide (2\%) vs. SU (11\%), } \\
\text { fewer with liraglutide }\end{array}$ \\
\hline Brady/2014 [69] & $\begin{array}{l}\text { Comparison of SU with the } \\
\text { liraglutide; MTF in both arms }\end{array}$ & $\begin{array}{l}\text { Open-label, randomized, trial } \\
N=99\end{array}$ & $\begin{array}{l}\text { Self-recorded blood } \\
\text { glucose } \leq 3.9 \mathrm{mmol} / \mathrm{L} \text { : } \\
\text { - Liraglutide }(25 \%) \text { vs. } \\
\text { SU }(46.2 \%), p<0.0001 \\
\text { Weight change up to 3rd week of } \\
\text { Ramadan: } \\
\text { - Liraglutide }(-0.42 \mathrm{~kg}) \text { vs. SU } \\
\text { (- } 2.23 \mathrm{~kg}), p=0.02 \\
\text { Change in diastolic blood } \\
\text { pressure } 12 \text { weeks post- } \\
\text { Ramadan: } \\
\text { - Liraglutide }(-6.18 \mathrm{mmHg}) \text { vs. } \\
\text { SU ( } 0.65 \mathrm{mmHg}), p=0.03\end{array}$ \\
\hline Khalifa/2015 [59] & $\begin{array}{l}\text { To assess the safety and efficacy of } \\
\text { liraglutide during Ramadan }\end{array}$ & $\begin{array}{l}\text { Observational study } \\
N=111\end{array}$ & $\begin{array}{l}\text { - Hypoglycaemia reported in } 18 \\
\text { patients }(16.2 \%) \\
\text { - } \text { HbA }_{1 \mathrm{c}} \Delta \text { from } 8.0 \text { to } 7.4 \% \\
(p=0.000)\end{array}$ \\
\hline $\begin{array}{l}\text { Hassanein } / 2018 \\
\quad[70]\end{array}$ & $\begin{array}{l}\text { To examine the hypoglycaemic } \\
\text { potential of lixisenatide as an add- } \\
\text { on to BI }\end{array}$ & $\begin{array}{l}\text { Phase 4, randomized, open- } \\
\text { label, parallel-group clinical } \\
\text { trial } \\
N=184\end{array}$ & $\begin{array}{l}\text { Hypoglycaemia: } \\
\text { - Lixisenatide + BI ( } 4.3 \% \text {; } \\
\text { 4/92) vs. SU + BI }(17.4 \% ; \\
16 / 92) \\
\mathrm{HbA}_{1 \mathrm{c}} \Delta \text { was similar- } \\
\text { - } \mathrm{LS} \pm \mathrm{SE}-0.4 \pm 0.1 \% \text { for } \\
\text { lixisenatide }+\mathrm{BI} \\
\text { - } \mathrm{LS} \pm \mathrm{SE}-0.5 \pm 0.1 \% \text { for } \mathrm{SU} \\
+\mathrm{BI}\end{array}$ \\
\hline
\end{tabular}

$B I$ Basal insulin, $L E$ least squares, $S E$ standard error 
Table 10 Summary of evidence for sodium-glucose cotransporter-2 inhibitors during Ramadan

\begin{tabular}{|c|c|c|c|}
\hline $\begin{array}{l}\text { First author } \\
\text { of study/ } \\
\text { publication } \\
\text { year }\end{array}$ & Intervention & Characteristics & Outcomes \\
\hline $\begin{array}{c}\text { Wan Seman/ } \\
2016[71]\end{array}$ & $\begin{array}{l}\text { Comparison of dDapagliflozin to } \\
\text { SU; MTF in both arms }\end{array}$ & $\begin{array}{l}\text { Open-label RCT, Malaysia } \\
N=110\end{array}$ & $\begin{array}{l}\mathrm{HbA}_{1 \mathrm{c}} \Delta: \\
\text { - Dapagliflozin }(0.05 \%) \text { vs. SU }(0.32 \%) \\
\text { Hypoglycaemia: } \\
\text { - Dapagliflozin }(6.9 \%) \text { vs. SU }(28.8 \%) \\
p=0.002\end{array}$ \\
\hline $\begin{array}{l}\text { Hassanein/ } \\
2017[60]\end{array}$ & $\begin{array}{l}\text { Comparison of canagliflozin to } \\
\text { SU; MTF } \pm \text { DPP4i in both } \\
\text { arms }\end{array}$ & $\begin{array}{l}\text { Non-randomized, parallel- } \\
\text { cohort, prospective, } \\
\text { comparative, } \\
\text { observational study } \\
N=321\end{array}$ & $\begin{array}{l}\mathrm{HbA}_{1 \mathrm{c}} \Delta: \\
\text { - Canagliflozin }(0.04 \%) \text { vs. SU }(0.20 \%) \\
\text { Hypoglycaemia: } \\
\text { - Canagliflozin }(3.7 \%) \text { vs. SU }(13.2 \%), \\
p=0.009 \\
\text { Volume depletion: } \\
\text { - Canagliflozin }(9.3 \%) \text { vs. SU }(3.8 \%)\end{array}$ \\
\hline $\begin{array}{c}\text { Shao/2018 } \\
\text { [63] }\end{array}$ & $\begin{array}{l}\text { Study of the effect of SGLT-2 } \\
\text { inhibitor use on ketonaemia, } \\
\text { blood pressure and renal } \\
\text { function }\end{array}$ & $\begin{array}{l}\text { Single-centre prospective } \\
\text { observational controlled } \\
\text { cohort study } \\
N=68\end{array}$ & $\begin{array}{l}\text { Continued use of SGLT2 inhibitors } \\
\text { during Ramadan did not increase } \\
\text { ketonemia, nor increase risk of eGFR } \\
\text { deterioration and hypoglycaemia } \\
\text { Mean change in: } \\
\text { - Weight: }-1.8 \text { vs. }-1.1 \mathrm{~kg} \\
(p=0.205) \\
\text { - eGFR: }-6.0 \text { vs. }-4.2 \mathrm{~mL} / \mathrm{min} / \\
1.73 \mathrm{~m}^{2}(p=0.399) \\
\text { - Systolic BP: }-8.1 \text { vs. }-10.4 \mathrm{mmHg} \\
(p=0.569) \\
\text { - Diastolic BP: }-3.7 \text { vs. }-3.5 \mathrm{mmHg} \\
(p=0.934) \\
\text { - Plasma } \beta \text {-hydroxybutyrate: }-0.01 \text { vs. } \\
-0.02 \mathrm{mmol} / \mathrm{L}(p=0.649)\end{array}$ \\
\hline
\end{tabular}

$B P$ Blood pressure, $e G F R$ estimated glomerular filtration rate

\section{Chronic Kidney Disease}

Muslims with diabetes have a high risk of developing chronic kidney disease (CKD). Fasting during Ramadan has been reviewed elsewhere for this patient population, but there is a concern about deterioration in renal disease in susceptible patients due to dehydration [147]. Frequent and prolonged hypoglycaemia has been reported in $\mathrm{T} 2$ diabetes patients with CKD stage 3 who fast during Ramadan based on FreeStyle Libre flash continuous glucose 
monitoring (FSL-CGM) [148]. However, there is little robust evidence available to guide clinicians, i.e. in the form of RCTs or large-scale observational studies in patients with CKD; consequently, advice may have to be guided by the duration of fasting. In equatorial countries, the duration of fasting varies little from year to year and is stable at around $12-14 \mathrm{~h}$, whereas in temperate countries, the duration of fasting may vary from $8 \mathrm{~h}$ in the winter to $20 \mathrm{~h}$ in the summer. In the absence of adequate evidence, HCPs may have to give advice based on best available guidance. The IDF-DAR Ramadan and Diabetes guidelines classifies people with CKD as "High" or "Very High" risk, and hence it seems reasonable for a clinician to suggest to a person with CKD stages 3-5 that they should avoid fasting. Patients who wish to fast despite advice to the contrary, however, should be supported to do so safely. Advice to such patients will include encouragement to drink plenty of fluids during the non-fasting periodperhaps a measured amount each day, depending on fluid status-and to check electrolytes and creatinine in the middle of the fasting month to aid those with advanced CKD in deciding whether they should continue fasting. Whilst a number of studies of people on dialysis suggest that some people are able to fast, fasting amongst patients on dialysis should not be encouraged. People with stable renal transplants on stable immunosuppression, however, are probably able to fast safely providing they are monitored carefully by their transplant team before, during and after Ramadan.

\section{Pregnancy}

Although exempt, many pregnant Muslim women insist on fasting during the month of Ramadan. A large meta-analysis of 22 studies involving 31,373 pregnancies looked at outcomes of pregnancy during Ramadan [149]. Primary outcomes for this study were perinatal mortality, preterm birth (before 37 weeks of pregnancy) and small for gestational age (SGA) infants (as defined by each study or below the tenth centile for gestational age). Secondary outcomes included stillbirth, neonatal death, maternal death (the death of the mother during pregnancy or the first 6 weeks postnatally), hypertensive disorders of pregnancy, gestational diabetes, congenital abnormalities, serious neonatal morbidity, birth weight (continuous variable), low birth weight $(<2500 \mathrm{~g})$, very low birth weight $(<1500 \mathrm{~g})$, extremely preterm birth $(<28$ weeks gestation) and placental weight. Of the co-primary outcomes, only for preterm birth was there sufficient data, showing no significant effect of fasting. Data were available for some secondary outcomes, including birth weight, placental weight and low birth weight; only placental weight was significantly reduced by Ramadan [149]. However, this result was dominated by one study [150]. A small study looked at glycaemic control among pregnant women with diabetes on insulin who fasted during Ramadan and concluded that women were able to fast safely without any adverse effects on their diabetes control [151].

We therefore conclude that fasting during Ramadan while pregnant is an important personal decision and that all potential risks to mother and foetus should be explained to the mother. A more cautious stance is warranted, particularly when co-morbidities are present. Those who insist on fasting should be managed by an expert team and receive focussed education relating to self-management skills, such as modifications to diet and insulin regimens and frequent blood glucose monitoring to ensure good pregnancy outcomes. Guidance on terminating the fast and abstaining from subsequent fasts should also be clearly communicated, with emphasis that in the appropriate circumstances this is a responsible, entirely valid and indeed recommended action from a Shari'ah perspective [96].

\section{Other Forms of Diabetes Mellitus}

There is presently no evidence on the management of diabetes during Ramadan fasting for specific types of diabetes, such as monogenic diabetes syndromes, neonatal diabetes mellitus (NDM) and MODY, diabetes secondary to pancreatic disease (cystic fibrosis or pancreatitis), medications such as glucocorticoids, human immunodeficiency virus treatment or post- 
transplantation diabetes mellitus, to allow for the creation of specific guidance.

Treatment is based on first principles and is determined by the clinical presentation and laboratory parameters. For example, pancreatic exocrine insufficiency may present in up to $1.8 \%$ of patients newly diagnosed with diabetes; this tends to be a more brittle form of diabetes, requiring early insulin therapy [152]. Given the rapid fluctuation in glucose control, many patients with this condition may require MDI and should be treated in Ramadan as one would treat a person with T1 diabetes. MODY affects $2 \%$ of all patients with diabetes aged $\leq 20$ years [153]. With the exception of glucokinaseMODY (MODY 2), which is the mildest form of MODY, all other forms mimic T1 diabetes or T2 diabetes in terms of clinical course and complication rates and should be treated as such during Ramadan.

\section{Newer Technologies}

Newer technologies relevant and exclusive to patients with $\mathrm{T} 1$ diabetes has been discussed in the section "Type 1 diabetes: Education and Management". The use of FSL-CGM in high-risk T1/T2 diabetes patients $(n=169)$ has been shown to aid optimization of glycaemic control without compromising weight, blood pressure or renal function [154]. The authors of this study reported a higher incidence of hypoglycaemia. Similarly, use of FSL-CGM in T2 patients with stable CHD during fasting in Ramadan showed a significant improvement in the $\mathrm{HbA}_{1 \mathrm{c}}$ and a higher incidence of prolonged hypoglycaemia, which was not associated with any adverse cardiovascular effects [88]. The limitations of these studies are that they were not controlled, the accuracy of FSL-CGM in fasting patients is not studied and there was no correlation with SMBG. We conclude that FSLCGM may be considered in high-risk T2 diabetes patients who insist on fasting.

\section{Post-Bariatric Patients}

Bariatric surgery is being increasingly performed in patients with morbid obesity and diabetes
[155]. Fasting in these patients can put them at risk of malnutrition and dehydration. Fasting has been shown to be well tolerated in patients who undergo sleeve gastrectomy [156]. We conclude that this group of patients should be supported in fasting with adequate advice on nutrition, hydration and medication changes.

\section{The Elderly}

The reduced physiological reserve associated with aging can put frail elderly patients at greater risk of fasting-associated medical complications. Although elderly people with comorbidities are stratified in the high-risk category, old age on its own is not considered to be an independent risk factor for fasting.

In elderly patients with diabetes, there is an increased prevalence of visual impairment from retinal disease, cataracts, glaucoma; gait disturbances from peripheral neuropathy, previous amputation or stroke; cardiovascular disease; cognitive dysfunction; mood disturbances; and sarcopenia [157]. All of these conditions can adversely impact the ability of an elderly person to fast safely.

Fasting can adversely affect postural control of elderly people; this is worse in those who are habitual fallers pre-Ramadan [158]. During Ramadan, there is partial sleep deprivation, which can adversely affect cognitive function, attention and memory [159].

In the pre-Ramadan risk assessment, a baseline assessment of functional capacity, mood and cognition is essential to assist the decisionmaking process on fasting in the elderly and for future planning. A pre-Ramadan fasting programme consisting of planned changes in mealtimes and altered sleeping habits can help the elderly adapt to the changes during Ramadan. Particular emphasis is to be laid on maintaining sleep duration by going to bed early and on avoiding unaccustomed surfaces and inadequate environments, such as wet surfaces and reduced ambient lighting, to minimize the risk of falling [158]. A review of all medications, including hypoglycaemic agents with varying hypoglycaemic potential, is essential. 


\section{COVID-19 Infection-See Commentary (https://doi.org/10.1007/s13300-020- 00887-x)}

In light of the COVID-19 pandemic, individuals from a Black, Asian and Minority Ethnic (BAME) background and with obesity and diabetes appear to be more at risk for adverse outcomes. The concerns and risks raised, and in particular how one should manage such patients intending to fast during Ramadan, are discussed in the commentary accompanying this review.

\section{CONCLUSIONS}

Every year millions of Muslims fast, often doing so contrary to medical advice. Many patients admit to a do-it-yourself approach to diabetes management during Ramadan, largely due to under-appreciation of the risks and implications of the rigors of fasting on their diabetes, and the effects of antihyperglycaemic agents on their blood glucose levels in the fasting state. Many patients attempt to simply endure the difficulty in controlling the blood glucose levels within a defined time period $\leq 30$ days.

Part of the issue may also lie with the perceived inability of HCPs to grasp the religious sensitivities in relation to disease management when it comes to Muslims [160]. Thus, to mitigate the above, the pre-Ramadan assessment is crucial for the purpose of education, patient self-empowerment, medication adjustments and general advice, all with the aim to ensure a safe Ramadan experience. Those in the high- to very high-risk category should be closely supported by HCPs.

Although there is a conspicuous lack of RCTs, there is sufficient evidence across the different classes of agents in terms of safety and efficacy to support the patient and the HCP with informed decision-making. Ultimately, Ramadan provides an excellent opportunity for engagement between the HCP and the patient to discuss important dietary, lifestyle and medication changes, to improve their control in the short-term during Ramadan, and in the longterm, to prevent complications. If observants can sustain the metabolic gains achieved by
Ramadan fasting by continuing to adhere to the dietary discipline and behavioural changes over longer periods post-Ramadan, then there is a potential for long-term health dividends, reflecting as a reduction in the risk of complications, and improvement in physical and mental health and general well-being.

\section{Links to resources}

Ramadan and Diabetes. Diabetes UK: https://www.diabetes.org.uk/guide-todiabetes/managing-your-diabetes/ ramadan.

Ramadan Rapid Review - British Islamic Medical Association: https://britishima. org/ramadan-rapid-review/.

Guidelines for healthcare professionals: diabetes and Ramadan practical guidelines. International Diabetes Federation: https://www.idf.org/ouractivities/education/diabetes-andramadan/healthcare-professionals.html.

Guidelines for people with diabetesInternational Diabetes Federation: https:// www.idf.org/our-activities/education/ diabetes-and-ramadan/people-livingwith-diabetes.html.

'Can I fast with diabetes during Ramadan?'. Diabetes Voice, International Diabetes Federation: https:// diabetesvoice.org/en/caring-for-diabetes/ can-i-fast-with-diabetes-during-ramadan/.

Ramadan and Diabetes: A guide for patients. Muslim Council Britain: http:// www.mcb.org.uk/wp-content/uploads/ 2014/06/Ramadan-and-diabetes-A-guidefor-patients-2013.pdf.

\section{ACKNOWLEDGEMENTS}

Funding. No funding or sponsorship was received for the write up or publication of this article. 
Authorship. All named authors meet the International Committee of Medical Journal Editors (ICMJE) criteria for authorship for this article, take responsibility for the integrity of the work as a whole, and have given their approval for this version to be published.

Disclosures. Syed Haris Ahmed, Tahseen A Chowdhury, Sufyan Hussain, Ateeq Syed, Ali Karamat, Ahmed Helmy, Salman Waqar, Samina Ali, Ammarah Dabhad, Susan T Seal, Anna Hodgkinson, Shazli Azmi and Nazim Ghouri have nothing to disclose.

Compliance with Ethics Guidelines. This article is based on previously conducted studies and does not contain any studies with human participants or animals performed by any of the authors.

Data Availability. Data sharing is not applicable to this article as no datasets were generated or analysed during the current study.

Open Access. This article is licensed under a Creative Commons Attribution-NonCommercial 4.0 International License, which permits any non-commercial use, sharing, adaptation, distribution and reproduction in any medium or format, as long as you give appropriate credit to the original author(s) and the source, provide a link to the Creative Commons licence, and indicate if changes were made. The images or other third party material in this article are included in the article's Creative Commons licence, unless indicated otherwise in a credit line to the material. If material is not included in the article's Creative Commons licence and your intended use is not permitted by statutory regulation or exceeds the permitted use, you will need to obtain permission directly from the copyright holder. To view a copy of this licence, visit http:// creativecommons.org/licenses/by-nc/4.0/.

\section{REFERENCES}

1. Ghouri N, Gatrad R, Sattar N, Dhami S, Sheikh A. Summer-winter switching of the Ramadan fasts in people with diabetes living in temperate regions. Diabet Med. 2012;29(6):696-7.

2. Aadil N, Houti IE, Moussamih S. Drug intake during Ramadan. Br Med J. 2004;329(7469):778-82.

3. Wilhelmi de Toledo F, Grundler F, Bergouignan A, Drinda S, Michalsen A. Safety, health improvement and well-being during a 4 to 21-day fasting period in an observational study including 1422 subjects. PLoS ONE. 2019;14(1):e0209353.

4. Beshyah SA. Fasting during the month of ramadan for people with diabetes: medicine and figh united at last. Ibnosina J Med Biomed Sci. 2009;1(2):58-60.

5. Abu'"l-Ikhlas al-Shurunbulali. Fasting ascent to felicity. In: Ascent to felicity Maraqi 'l-Sa'adat: a manual on Islamic creed and Hanafi jurisprudence. 1st edn. London: White Thread Press. 2010. pp 135-8.

6. Babineaux SM, Toaima D, Boye KS, et al. Multicountry retrospective observational study of the management and outcomes of patients with Type 2 diabetes during Ramadan in 2010 (CREED). Diabet Med. 2015;32(6):819-28.

7. Salti I, Bénard E, Detournay B, et al. A populationbased study of diabetes and its characteristics during the fasting month of ramadan in 13 countries: Results of the epidemiology of diabetes and Ramadan 1422/2001 (EPIDIAR) study. Diabetes Care. 2004;27(10):2306-11.

8. Anton SD, Moehl K, Donahoo WT, Marosi K, Lee SA, Mainous AG 3rd, et al. Flipping the metabolic switch: understanding and applying the health benefits of fasting. Obesity (Silver Spring). 2018;26(2):254-68.

9. Ramlo-Halsted BA, Edelman SV. The natural history of type 2 diabetes. Implications for clinical practice. Prim Care. 1999;26(4):771-89.

10. Taylor R. Pathogenesis of type 2 diabetes: tracing the reverse route from cure to cause. Diabetologia. 2008;51(10):1781-9.

11. Steven S, Hollingsworth KG, Al-Mrabeh A, Avery L, Aribisala B, Caslake M, et al. Very low-calorie diet and 6 months of weight stability in type 2 diabetes: pathophysiological changes in responders and nonresponders. Diabetes Care [Internet]. 2016;39(5):808 LP-815. http://care. diabetesjournals.org/content/39/5/808.abstract. 
12. Cryer PE, Davis SN, Shamoon H. Hypoglycemia in diabetes. Diabetes Care. 2003;26(6):1902-12.

13. Amiel SA, Sherwin RS, Simonson DC, Tamborlane WV. Effect of intensive insulin therapy on glycemic thresholds for counterregulatory hormone release. Diabetes. 1988;37(7):901-7.

14. Boyle PJ, Schwartz NS, Shah SD, Clutter WE, Cryer PE. Plasma glucose concentrations at the onset of hypoglycemic symptoms in patients with poorly controlled diabetes and in nondiabetics. N Engl J Med. 1988;318(23):1487-92.

15. Unger $\mathrm{RH}$, Cherrington AD. Glucagonocentric restructuring of diabetes: a pathophysiologic and therapeutic makeover. J Clin Invest. 2012;122(1): 4-12.

16. Mannucci E, Pala L, Monami M, et al. Glucagon-like peptide-1 response to meals and post-prandial hyperglycemia in Type 2 diabetic patients. J Endocrinol Invest. 2010;33(3):147-50.

17. Lessan N, Hannoun Z, Hasan H, Barakat MT. Glucose excursions and glycaemic control during Ramadan fasting in diabetic patients: insights from continuous glucose monitoring (CGM). Diabetes Metab. 2015;41(1):28-36.

18. Gill S, Panda S. A Smartphone app reveals erratic diurnal eating patterns in humans that can be modulated for health benefits. Cell Metab. 2015;22(5):789-98.

19. el Ati J, Beji C, Danguir J. Increased fat oxidation during Ramadan fasting in healthy women: an adaptative mechanism for body-weight maintenance. Am J Clin Nutr. 1995;62(2):302-7.

20. Husain R, Duncan MT, Cheah SH, Ch'ng SL. Effects of fasting in Ramadan on tropical Asiatic Moslems. Br J Nutr. 1987;58(1):41-8.

21. Sweileh N, Schnitzler A, Hunter GR, Davis B. Body composition and energy metabolism in resting and exercising muslims during Ramadan fast. J Sports Med Phys Fitness. 1992;32(2):156-63.

22. Stannard SR, Thompson MW. The effect of participation in Ramadan on substrate selection during submaximal cycling exercise. J Sci Med Sport. 2008;11(5):510-7.

23. Bouhlel E, Salhi $\mathrm{Z}$, Bouhlel $\mathrm{H}$, et al. Effect of Ramadan fasting on fuel oxidation during exercise in trained male rugby players. Diabetes Metab. 2006;32(6):617-24.

24. Fernando HA, Zibellini J, Harris RA, Seimon RV, Sainsbury A. Effect of Ramadan fasting on weight and body composition in healthy non-athlete adults: a systematic review and meta-analysis. Nutrients. 2019;11(2):478.

25. Sadeghirad B, Motaghipisheh S, Kolahdooz F, Zahedi MJ, Haghdoost AA. Islamic fasting and weight loss: a systematic review and meta-analysis. Public Health Nutr. 2014;17(2):396-406.

26. Hajek P, Myers K, Dhanji A-R, West O, McRobbie H. Weight change during and after Ramadan fasting. J Public Health (Oxf). 2012;34(3):377-81.

27. Faris MA-IE, Kacimi S, Al-Kurd RA, et al. Intermittent fasting during Ramadan attenuates proinflammatory cytokines and immune cells in healthy subjects. Nutr Res. 2012;32(12):947-55.

28. de Groot S, Pijl H, van der Hoeven JJM, Kroep JR. Effects of short-term fasting on cancer treatment. J Exp Clin Cancer Res. 2019;38(1):209.

29. Habbal R, Azzouzi L, Adnan K, Tahiri A, Chraibi N. Variations of blood pressure during the month of Ramadan. Arch Mal Coeur Vaiss. 1998;91(8):995-8.

30. Perk G, Ghanem J, Aamar S, Ben-Ishay D, Bursztyn $M$. The effect of the fast of Ramadan on ambulatory blood pressure in treated hypertensives. J Hum Hypertens. 2001;15(10):723-5.

31. Ural E, Kozdag G, Kilic T, et al. The effect of Ramadan fasting on ambulatory blood pressure in hypertensive patients using combination drug therapy. J Hum Hyperten. 2008;22:208-10.

32. Ajabnoor GM, Bahijri S, Borai A, Abdulkhaliq AA, Al-Aama JY, Chrousos GP. Health impact of fasting in Saudi Arabia during Ramadan: association with disturbed circadian rhythm and metabolic and sleeping patterns. PLoS ONE. 2014;9(5):e96500.

33. Feizollahzadeh S, Rasuli J, Kheirouri S, Alizadeh M. Augmented plasma adiponectin after prolonged fasting during ramadan in men. Heal Promot Perspect. 2014;4(1):77-81.

34. Haouari M, Haouari-Oukerro F, Sfaxi A, Ben Rayana $\mathrm{MCH}$, Kâabachi N, Mbazâa A. How ramadan fasting affects caloric consumption, body weight, and circadian evolution of cortisol serum levels in young, healthy male volunteers. Horm Metab Res. 2008;40(8):575-7.

35. International Diabetes Federation. IDF diabetes atlas, ninth edition 2019. https://www.idf.org/ aboutdiabetes/what-is-diabetes/facts-figures.html. Accessed 4 July 2020.

36. International Diabetes Federation. Diabetes and Ramadan: practical guidance. https://www. worlddiabetesfoundation.org/global-search?search_ 
api_views_fulltext=sites $\% 20$ default $\% 20$ files $\%$ 20IDF. Accessed 12 May 2020.

37. Lipka M, Hackett C. Why Muslims are the world's fastest-growing religious group. http://www. pewresearch.org/fact-tank/2017/04/06/whymuslims-are-the-worlds-fastest-growing-religiousgroup/. Accessed 12 May 2020.

38. Basu S, Stuckler D, McKee M, Galea G. Nutritional determinants of worldwide diabetes: an econometric study of food markets and diabetes prevalence in 173 countries. Public Health Nutr. 2013;16(1): 179-86.

39. Cheema A, Adeloye D, Sidhu S, Sridhar D, Chan KY. Urbanization and prevalence of type 2 diabetes in Southern Asia: a systematic analysis. J Glob Health. 2014;4(1):10404.

40. Kodama S, Horikawa C, Fujihara K, et al. Quantitative relationship between body weight gain in adulthood and incident type 2 diabetes: a metaanalysis. Obes Rev. 2014;15(3):202-14.

41. Hossain P, Kawar B, El Nahas M. Obesity and diabetes in the developing world-a growing challenge. N Engl J Med. 2007;356(3):213-5.

42. Al-Arouj M, Bouguerra R, Buse J, et al. Recommendations for management of diabetes during Ramadan. Diabetes Care. 2005;28(9):2305-11.

43. Al-Arouj M, Assaad-Khalil S, Buse J, et al. Recommendations for management of diabetes during Ramadan: update 2010. Diabetes Care. 2010;33(8): 1895-902.

44. Ibrahim M, Abu Al Magd M, Annabi FA, et al. Recommendations for management of diabetes during Ramadan: update 2015. BMJ Open Diabetes Res Care. 2015;3(1):e000108. http://drc.bmj.com/ content/3/1/e000108.abstract.

45. Ali S, Davies MJ, Brady EM, et al. Guidelines for managing diabetes in Ramadan. Diabetic Medicine. 2016;33(10):1315-29.

46. Hassanein M, Al-Arouj M, Hamdy O, et al. Diabetes and Ramadan: practical guidelines. Diabetes Res Clin Pract. 2017;126:303-16.

47. Ibrahim M, Davies MJ, Ahmad E, et al. Recommendations for management of diabetes during Ramadan: update 2020, applying the principles of the ADA/EASD consensus. BMJ Open Diabetes Res Care. 2020;8(1):1-14. http://www.ncbi.nlm.nih. gov/pubmed/32366501.

48. Jabbar A, Hassanein M, Beshyah SA, Boye KS, Yu M, Babineaux SM. CREED study: hypoglycaemia during Ramadan in individuals with type 2 diabetes mellitus from three continents. Diabetes Res Clin Pract. 2017;132:19-26.

49. Al Awadi FF, Echtay A, Al Arouj M, et al. Patterns of diabetes care among people with type 1 diabetes during Ramadan: an international prospective study (DAR-MENA T1DM). Adv Ther. 2020;37(4): 1550-63.

50. Hassanein M, Al Awadi FF, El Hadidy KES, et al. The characteristics and pattern of care for the type 2 diabetes mellitus population in the MENA region during Ramadan: an international prospective study (DAR-MENA T2DM). Diabetes Res Clin Pract. 2019.

51. Chowdhury A, Khan H, Shawarna SL, Chowdhury T. A survey of patients with type 2 diabetes and fasting outcomes during Ramadan 2016 in London: the East London Diabetes in Ramadan Survey. Br J Diabetes. 2017;17(4):149-51.

52. Aydin N, Kul S, Karadağ G, Tabur S, Araz M. Effect of Ramadan fasting on glycaemic parameters \& body mass index in type II diabetic patients: a metaanalysis. Indian J Med Res. 2019;150(6):546-56.

53. Beshyah S, Badi A, El-Ghul A, Gabroun A, Dougman $\mathrm{K}$, Eledrisi M. The year in "Ramadan Fasting and Health" (2018): a narrative review. Ibnosina J Med Biomed Sci. 2019;11(4):151. http://www.ijmbs.org/ article.asp?issn=1947-489X.

54. Mattoo V, Milicevic Z, Malone JK, et al. A comparison of insulin lispro Mix25 and human insulin $30 / 70$ in the treatment of type 2 diabetes during Ramadan. Diabetes Res Clin Pract. 2003;59(2): 137-43.

55. Cesur M, Corapcioglu D, Gursoy A, et al. A comparison of glycemic effects of glimepiride, repaglinide, and insulin glargine in type 2 diabetes mellitus during Ramadan fasting. Diabetes Res Clin Pract. 2007;75(2):141-7.

56. Bakiner O, Ertorer ME, Bozkirli E, Tutuncu NB, Demirag NG. Repaglinide plus single-dose insulin glargine: a safe regimen for low-risk type 2 diabetic patients who insist on fasting in Ramadan. Acta Diabetol. 2009;46(1):63-5.

57. Matas AJ, Gillingham KJ, Humar A, et al. Posttransplant diabetes mellitus and acute rejection: impact on kidney transplant outcome. Transplantation. 2008;85(3):338-43.

58. Hassanein M, Hanif W, Malik W, et al. Comparison of the dipeptidyl peptidase- 4 inhibitor vildagliptin and the sulphonylurea gliclazide in combination with metformin, in Muslim patients with type 2 diabetes mellitus fasting during Ramadan: results of 
the VECTOR study. Curr Med Res Opin. 2011;27(7): 1367-74.

59. Khalifa AA, Rashid AOE, Bashier A. Safety and efficacy of liraglutide as an add-on therapy to pre-existing anti-diabetic regimens during Ramadan, a prospective observational trial. J Diabetes Metab. 2015;6(9):1-6.

60. Hassanein M, Echtay A, Hassoun A, et al. Tolerability of canagliflozin in patients with type 2 diabetes mellitus fasting during Ramadan: Results of the Canagliflozin in Ramadan Tolerance Observational Study (CRATOS). Int J Clin Pract. 2017;71(10):e12991. https://doi.org/10.1111/ijcp. 12991.

61. Aldawi N, Darwiche G, Abusnana S, Elbagir M, Elgzyri T. Initial increase in glucose variability during Ramadan fasting in non-insulin-treated patients with diabetes type 2 using continuous glucose monitoring. Libyan J Med. 2019;14(1):1535747.

62. Bonakdaran SH, Khajeh-Dalouie M. The effects of fasting during Ramadan on glycemic excursions detected by continuous glucose monitoring system (CGMS) in patients with type 2 diabetes. Med J Malaysia. 2011;66(5):447-50.

63. Shao Y, Lim GJ, Chua CL, et al. The effect of Ramadan fasting and continuing sodium-glucose co-transporter-2 (SGLT2) inhibitor use on ketonemia, blood pressure and renal function in Muslim patients with type 2 diabetes. Diabetes Res Clin Pract. 2018;142:85-91.

64. Hassanein M, Echtay AS, Malek R, et al. Original paper: efficacy and safety analysis of insulin degludec/insulin aspart compared with biphasic insulin aspart 30: A phase 3, multicentre, international, open-label, randomised, treat-to-target trial in patients with type 2 diabetes fasting during. Diabetes Res Clin Pract. 2018;135:218-26.

65. Gray LJ, Dales J, Brady EM, Khunti K, Hanif W, Davies MJ. Safety and effectiveness of non-insulin glucose-lowering agents in the treatment of people with type 2 diabetes who observe Ramadan: a systematic review and meta-analysis. Diabetes Obes Metab. 2015;17(7):639-48.

66. Aravind SR, Ismail SB, Balamurugan R, et al. Hypoglycemia in patients with type 2 diabetes from India and Malaysia treated with sitagliptin or a sulfonylurea during Ramadan: a randomized, pragmatic study. Curr Med Res Opin. 2012;28(8):1289-96.

67. Hassanein M, Abdallah K, Schweizer A. A doubleblind, randomized trial, including frequent patientphysician contacts and Ramadan-focused advice, assessing vildagliptin and gliclazide in patients with type 2 diabetes fasting during Ramadan: the
STEADFAST study. Vasc Health Risk Manag. 2014;10:319-26.

68. Azar ST, Echtay A, Wan Bebakar WM, et al. Efficacy and safety of liraglutide compared to sulphonylurea during Ramadan in patients with type 2 diabetes (LIRA-Ramadan): a randomized trial. Diabetes Obes Metab. 2016;18(10):1025-33.

69. Brady EM, Davies MJ, Gray LJ, et al. A randomized controlled trial comparing the GLP-1 receptor agonist liraglutide to a sulphonylurea as add on to metformin in patients with established type 2 diabetes during Ramadan: the Treat 4 Ramadan Trial. Diabetes Obes Metab. 2014;16(6):527-36.

70. Hassanein MM, Sahay R, Hafidh K, et al. Safety of lixisenatide versus sulfonylurea added to basal insulin treatment in people with type 2 diabetes mellitus who elect to fast during Ramadan (LixiRam): an international, randomized, open-label trial. Diabetes Res Clin Pract. 2019;150:331-41.

71. Wan Seman WJ, Kori N, Rajoo S, et al. Switching from sulphonylurea to a sodium-glucose cotransporter2 inhibitor in the fasting month of Ramadan is associated with a reduction in hypoglycaemia. Diabetes Obes Metab. 2016;18(6):628-32.

72. AlAlwan I, Al Banyan A. Effects of Ramadan fasting on children with type 1 diabetes. Int J Diabetes Mellit. 2010;2(2):127-9.

73. Alamoudi R, Alsubaiee M, Alqarni A, et al. Comparison of insulin pump therapy and multiple daily injections insulin regimen in patients with type 1 diabetes during ramadan fasting. Diabetes Technol Ther. 2017.

74. Al-Agha AE, Kafi SE, Zain Aldeen AM, Khadwardi $\mathrm{RH}$. Flash glucose monitoring system may benefit children and adolescents with type 1 diabetes during fasting at Ramadan. Saudi Med J. 2017;38(4): 366-71.

75. Zabeen B, Tayyeb S, Benarjee B, et al. Fasting during Ramadan in adolescents with diabetes. Indian $\mathrm{J}$ Endocrinol Metab. 2014;18(1):44-7.

76. Ahmedani MY, Haque MS, Basit A, Fawwad A, Alvi SFD. Ramadan Prospective Diabetes Study: the role of drug dosage and timing alteration, active glucose monitoring and patient education. Diabet Med. 2012.

77. Elmehdawi R, Ehmida M, Elmagrehi H. Incidence of diabetic ketoacidosis during Ramadan fasting in Benghazi-Libya. Oman Med J. 2009;24(2):99-102.

78. Kadiki OA, Gerryo SE, Khan MM. Childhood diabetes mellitus in Benghazi (Libya). J Trop Pediatr. 1987;33(3):136-9. 
79. Norouzy A, Mohajeri SMR, Shakeri S, et al. Effect of Ramadan fasting on glycemic control in patients with Type 2 diabetes. J Endocrinol Invest. 2012;35(8):766-71.

80. Beano AM, Zmaili MA, Gheith ZH, et al. Predetermined anti-diabetic drug regimen adjustments during ramadan fasting: an observational study of safety. Endocrinol Metab (Seoul). 2017;32(2): 265-73.

81. Beshyah SA, Chowdhury TA, Ghouri N, Lakhdar AA. Risk of diabetic ketoacidosis during Ramadan fasting: a critical reappraisal. Diabetes Res Clin Pract. 2019;151:290-8.

82. Alabbood MH, Ho KW, Simons MR. The effect of Ramadan fasting on glycaemic control in insulin dependent diabetic patients: a literature review. Diabetes Metab Syndr. 2017;11(1):83-7.

83. Khalil AB, Beshyah SA, Abu Awad SM, et al. Ramadan fasting in diabetes patients on insulin pump therapy augmented by continuous glucose monitoring: an observational real-life study. Diabetes Technol Ther. 2012;14(9):813-8.

84. Saadatnia M, Zare M, Fatehi F, Ahmadi A. The effect of fasting on cerebral venous and dural sinus thrombosis. Neurol Res. 2009;31(8):794-8.

85. Assy MH, Awd M, Elshabrawy AM, Gharieb M. Effect of Ramadan fasting on incidence of cerebrovascular stroke in Egyptian patients with Type 2 Diabetes Mellitus. Diabetes Res Clin Pract. 2019;151:299-304.

86. Bouida W, Baccouche H, Sassi M, et al. Effects of Ramadan fasting on platelet reactivity in diabetic patients treated with clopidogrel. Thromb J [Internet]. 2017;15(1):15. https://doi.org/10.1186/ s12959-017-0138-0.

87. Salim I, Al Suwaidi J, Ghadban W, Alkilani H, Salam AM. Impact of religious Ramadan fasting on cardiovascular disease: a systematic review of the literature. Curr Med Res Opin. 2013;29(4):343-54.

88. Hassanein M, Rashid F, Elsayed M, et al. Assessment of risk of fasting during Ramadan under optimal diabetes care, in high-risk patients with diabetes and coronary heart disease through the use of FreeStyle Libre flash continuous glucose monitor (FSL-CGM). Diabetes Res Clin Pract. 2019;150: 308-14.

89. Almulhem M, Susarla R, Alabdulaali L, et al. The effect of Ramadan fasting on cardiovascular events and risk factors in patients with type 2 diabetes: a systematic review. Diabetes Res Clin Pract. 2020;159:107918.
90. Samad F, Qazi F, Pervaiz MB, et al. Effects of Ramadan fasting on blood pressure in normotensive males. J Ayub Med Coll Abbottabad. $2015 ; 27(2): 338-42$.

91. Norouzy A, Hasanzade Daloee M, Khoshnasab AH, et al. Trend of blood pressure in hypertensive and normotensive volunteers during Ramadan fasting. Blood Press Monit. 2017;22(5):253-7.

92. Salahuddin M, Sayed Ashfak AH, Syed SR, Badaam KMM S. Effect of Ramadan fasting on body weight, (BP) and biochemical parameters in middle aged hypertensive subjects: an observational trial. J Clin Diagn Res. 2014;8(3):16-8.

93. Mazidi M, Rezaie P, Chaudhri O, Karimi E, Nematy M. The effect of Ramadan fasting on cardiometabolic risk factors and anthropometrics parameters: a systematic review. Pak J Med Sci. 2015;31(5):1250-5.

94. Bouguerra R, Belkadhi A, Jabrane J, et al. Metabolic effects of the month of Ramadan fasting on type 2 diabetes. East Mediterr Health J. 2003;9(5-6): 1099-108.

95. Shehab A, Abdulle A, El Issa A, Al Suwaidi J, Nagelkerke N. Favorable changes in lipid profile: the effects of fasting after Ramadan. PLoS ONE. 2012;7(10):e47615.

96. Ghouri N, Hussain S, Mohammed R, et al. Diabetes, driving and fasting during Ramadan: the interplay between secular and religious law. BMJ Open Diabetes Res Care. 2018;6(1):e000520.

97. Hodgkinson A, Hussain S, South East London Area Prescribing Committee. South East London clinical guidance for the management of diabetes in Ramadan for healthcare professionals in primary care. 2019. https://www.lambethdiabetes.nhs.uk/ wp-content/uploads/Diabetes-management-inRamadan-Mar-2019.pdf. Accessed 13 May 2019.

98. Bravis V, Hui E, Salih S, Mehar S, Hassanein M, Devendra D. Ramadan Education and Awareness in Diabetes (READ) programme for Muslims with type 2 diabetes who fast during Ramadan. Diabet Med. 2010.

99. Eid YM, Sahmoud SI, Abdelsalam MM, Eichorst B. Empowerment-based diabetes self-management education to maintain glycemic targets during Ramadan fasting in people with diabetes who are on conventional insulin: a feasibility study. Diabetes Spectr. 2017;30(1):36-42.

100. Choudhary P, Campbell F, Joule N, Kar P. A Type 1 diabetes technology pathway: consensus statement for the use of technology in Type 1 diabetes. Diabet Med. 2019;36(5):531-8. 
101. Alsaeed D, Al-Kandari J, Al-Ozairi E. Experiences of people with type 1 diabetes fasting Ramadan following structured education: a qualitative study. Diabetes Res Clin Pract. 2019;153:157-65.

102. Hopkins D, Lawrence IAN, Mansell P, et al. Improved biomedical and psychological outcomes 1 year after structured education in flexible insulin therapy for people with type 1 diabetes the U.K. DAFNE experience. Diabetes Care. 2012;35(8): $1638-42$.

103. Riddell MC, Gallen IW, Smart CE, et al. Exercise management in type 1 diabetes: a consensus statement. Lancet Diabetes Endocrinol. 2017;5(5): 377-90.

104. Beshyah S, Habeb A, Deeb A, Elbarbary N. Ramadan fasting and diabetes in adolescents and children: a narrative review. Ibnosina $\mathrm{J}$ Med Biomed Sci. 2019;11(2):47.

105. Melo KFS, Bahia LR, Pasinato B, et al. Short-acting insulin analogues versus regular human insulin on postprandial glucose and hypoglycemia in type 1 diabetes mellitus: A systematic review and metaanalysis. Diabetol Metab Syndr. 2019;11(1):1-13. https://doi.org/10.1186/s13098-018-0397-3.

106. Ghouri N, Hussain S, Mohammed R, et al. Diabetes, driving and fasting during Ramadan: The interplay between secular and religious law. BMJ Open Diabetes Res Care. 2018;6(1):e000520. https://doi.org/ 10.1136/bmjdrc-2018-000520.

107. Kadiri A, Al-Nakhi A, El-Ghazali S, et al. Treatment of type 1 diabetes with insulin lispro during Ramadan. Diabetes Metab. 2001;27(4 Pt 1):482-6.

108. Alamoudi R, Alsubaiee M, Alqarni A, et al. Comparison of insulin pump therapy and multiple daily injections insulin regimen in patients with type 1 diabetes during ramadan fasting. Diabetes Technol Ther. 2017;19(6):349-54.

109. Loh HH, Lim LL, Loh HS, Yee A. Safety of Ramadan fasting in young patients with type 1 diabetes: A systematic review and meta-analysis. J Diabetes Investig. 2019.

110. Bin-Abbas BS. Insulin pump therapy during Ramadan fasting in type 1 diabetic adolescents. Ann Saudi Med. 2008;28:305-6.

111. Benbarka MM, Khalil AB, Beshyah SA, Marjei S, Awad SA. Insulin pump therapy in Moslem patients with type 1 diabetes during Ramadan fasting: an observational report. Diabetes Technol Ther. 2010;12(4):287-90.

112. Kaplan W, Afandi B. Blood glucose fluctuation during Ramadan fasting in adolescents with type 1 diabetes: findings of continuous glucose monitoring. Diabetes Care. 2015;38:e162-3.

113. Al-Ozairi E, El Samad A, Al Kandari J, Aldibbiat AM. Intermittent fasting could be safely achieved in people with type 1 diabetes undergoing structured education and advanced glucose monitoring. Front Endocrinol (Lausanne). 2019;10:1-9.

114. Elbarbary N. Effectiveness of the low-glucose suspend feature of insulin pump during fasting during Ramadan in type 1 diabetes mellitus. Diabetes Metab Res Rev. 2016;32:623-33. http://libweb. anglia.ac.uk/.

115. Bally L, Thabit H, Hovorka R. Glucose-responsive insulin delivery for type 1 diabetes: the artificial pancreas story. Int J Pharm. 2018;544(2):309-18.

116. Jennings P, Hussain S. Do-It-yourself artificial pancreas systems: a review of the emerging evidence and insights for healthcare professionals. J Diabetes Sci Technol. 2019;1932296819894296. https://doi. org/10.1177/1932296819894296.

117. Petrovski G, Al Khalaf F, Campbell J, Hussain K, Fisher H, Umer F. Glucose control during Ramadan fasting in a teenager with type 1 diabetes on MiniMed 670G hybrid closed-loop system. Acta Diabetol. 2020;57(1):105-7. https://doi.org/10.1007/ s00592-019-01414-6.

118. Hussain S, Choudhary P HD. Type 1 diabetes and fasting in Ramadan: time to rethink classification of risk? Lancet Diabetes Endocrinol. 2020.https://doi. org/10.1016/S2213-8587(20)30219-9.

119. Ibrahim M, Abu Al Magd M, Annabi FA, et al. Recommendations for management of diabetes during Ramadan: update 2015. BMJ Open Diabetes Res Care. 2015;3(1):1-9.

120. Gong L, Goswami S, Giacomini KM, Altman RB, Klein TE. Metformin pathways: pharmacokinetics and pharmacodynamics. Pharmacogenet Genomics. 2012;22(11):820-7.

121. Campbell LK, White JR, Campbell RK. Acarbose: its role in the treatment of diabetes mellitus. Ann Pharmacother. 1996;30(11):1255-62.

122. Duboc H, Coffin B, Siproudhis L. Disruption of circadian rhythms and gut motility: an overview of underlying mechanisms and associated pathologies. J Clin Gastroenterol. 2020;54(5):405-14.

123. Özkul C, Yalınay M, Karakan T. Islamic fasting leads to an increased abundance of Akkermansia muciniphila and Bacteroides fragilis group: a preliminary study on intermittent fasting. Turk J Gastroenterol. 2019;30(12):1030-5. 
124. Hauner $H$. The mode of action of thiazolidinediones. Diabetes Metab Res Rev. 2002;18(Suppl 2): S10-5.

125. Vasan S, Thomas N, Bharani, et al. A double-blind, randomized, multicenter study evaluating the effects of pioglitazone in fasting Muslim subjects during Ramadan. Int J Diabetes Dev Countries. 2006;26:7. https://doi.org/10.4103/0973-3930. 26882 .

126. Malaisse WJ. Mechanism of action of a new class of insulin secretagogues. Exp Clin Endocrinol Diabetes. 1999;107(Suppl):S140-3.

127. Anwar A, Azmi KN, Hamidon BB, Khalid BAK. An open label comparative study of glimepiride versus repaglinide in type 2 diabetes mellitus Muslim subjects during the month of Ramadan. Med J Malaysia. 2006;61(1):28-35. http://europepmc. org/abstract/MED/16708731.

128. Liang Y, Matschinsky FM. Mechanisms of action of nonglucose insulin secretagogues. Annu Rev Nutr. 1994;14:59-81.

129. Zargar AH, Siraj M, Jawa AA, Hasan M, Mahtab H. Maintenance of glycaemic control with the evening administration of a long acting sulphonylurea in male type 2 diabetic patients undertaking the Ramadan fast. Int J Clin Pract. 2010;64(8):1090-4.

130. Hassanein M, Al Sifri S, Shaikh S, et al. A real-world study in patients with type 2 diabetes mellitus treated with gliclazide modified-release during fasting: DIA-RAMADAN. Diabetes Res Clin Pract. 2020;163:108154.

131. Glimepiride in Ramadan (GLIRA) Study Group. The efficacy and safety of glimepiride in the management of type 2 diabetes in Muslim patients during Ramadan. Diabetes Care. 2005;28(2):421-2.

132. Aravind SR, Al Tayeb K, Ismail SB, et al. Hypoglycaemia in sulphonylurea-treated subjects with type 2 diabetes undergoing Ramadan fasting: a fivecountry observational study. Curr Med Res Opin. 2011;27(6):1237-42.

133. Mafauzy M. Repaglinide versus glibenclamide treatment of Type 2 diabetes during Ramadan fasting. Diabetes Res Clin Pract. 2002;58(1):45-53. https://doi.org/10.1016/S0168-8227(02)00104-3.

134. Khunti K, Chatterjee S, Gerstein HC, Zoungas S, Davies MJ. Do sulphonylureas still have a place in clinical practice? Lancet Diabetes Endocrinol. 2018;6(10):821-32.

135. Salti I. Efficacy and safety of insulin glargine and glimepiride in subjects with Type 2 diabetes before, during and after the period of fasting in Ramadan. Diabet Med. 2009;26(12):1255-61.

136. Akram J, De Verga V. Insulin lispro (Lys(B28), Pro(B29) in the treatment of diabetes during the fasting month of Ramadan. Ramadan Study Group. Diabet Med. 1999;16(10):861-6.

137. Soewondo P, Adam J, Sanusi H, Soeatmadji D. A multicenter, prospective, non-interventional evaluation of efficacy and safety of using biphasic insulin aspart as monotherapy, or in combination with oral hypoglycemic agent, in the treatment of type 2 diabetic patients before, during, \& after Ramadan. J Indon Med Assoc. 2009;59:574-9.

138. Hui E, Bravis V, Salih S, Hassanein M, Devendra D. Comparison of Humalog mix 50 with human insulin mix 30 in type 2 diabetes patients during Ramadan. Int J Clin Pract. 2010;64(8):1095-9.

139. Shehadeh N, Maor Y. Effect of a new insulin treatment regimen on glycaemic control and quality of life of Muslim patients with type 2 diabetes mellitus during Ramadan fast-an open label, controlled, multicentre, cluster randomised study. Int J Clin Pract. 2015;69(11):1281-8.

140. Kalra S. Insulin degludec and insulin degludec/insulin aspart in Ramadan: a single center experience. Indian J Endocrinol Metab. 2016;20(4):564-7.

141. Hassanein M, Akif Buyukbese M, Malek R, et al. Real-world safety and effectiveness of insulin glargine $300 \mathrm{U} / \mathrm{mL}$ in participants with type 2 diabetes who fast during Ramadan: the observational ORION study. Diabetes Res Clin Pract. 2020;108189. https://doi.org/10.1016/j.diabres.2020.108189.

142. Drucker DJ, Nauck MA. The incretin system: glucagon-like peptide-1 receptor agonists and dipeptidyl peptidase- 4 inhibitors in type 2 diabetes. Lancet. 2006;368(9548):1696-705.

143. Amori RE, Lau J, Pittas AG. Efficacy and safety of incretin therapy in type 2 diabetes: systematic review and meta-analysis. JAMA. 2007;298(2): 194-206.

144. Fulcher G, Matthews DR, Perkovic V, et al. Efficacy and safety of canagliflozin used in conjunction with sulfonylurea in patients with type 2 diabetes mellitus: a randomized. Controlled Trial. Diabetes Ther. 2015;6(3):289-302.

145. John M, Cerdas S, Violante R, et al. Efficacy and safety of canagliflozin in patients with type 2 diabetes mellitus living in hot climates. Int J Clin Pract. 2016;70(9):775-85.

146. Beshyah SA, Chatterjee S, Davies MJ. Use of SGLT2 inhibitors during Ramadan: a survey of physicians' 
views and practical guidance. $\mathrm{Br} \mathrm{J}$ Diabetes. 2016;16(1):20-4.

147. Ahmad S, Chowdhury TA. Fasting during Ramadan in people with chronic kidney disease: a review of the literature. Ther Adv Endocrinol Metab. 2019;10: 2042018819889019. https://doi.org/10.1177/ 2042018819889019

148. Alawadi F, Rashid F, Bashier A, et al. The use of Free Style Libre Continues Glucose Monitoring (FSLCGM) to monitor the impact of Ramadan fasting on glycemic changes and kidney function in high-risk patients with diabetes and chronic kidney disease stage 3 under optimal diabetes care. Diabetes Res Clin Pract. 2019;151:305-12.

149. Glazier JD, Hayes DJL, Hussain S, et al. The effect of Ramadan fasting during pregnancy on perinatal outcomes: a systematic review and meta-analysis. BMC Pregnancy Childbirth. 2018;18(1):421. https://doi.org/10.1186/s12884-018-2048-y.

150. Alwasel SH, Abotalib Z, Aljarallah JS, et al. Secular increase in placental weight in Saudi Arabia. Placenta. 2011;32(5):391-4.

151. Ismail NAM, Olaide Raji H, Abd Wahab N, Mustafa N, Kamaruddin NA, Abdul Jamil M. Glycemic control among pregnant diabetic women on insulin who fasted during Ramadan. Iran J Med Sci. 2011;36(4):254-9.

152. Wynne K, Devereaux B, Dornhorst A. Diabetes of the exocrine pancreas. J Gastroenterol Hepatol. 2019;34(2):346-54.

153. Pihoker C, Gilliam LK, Ellard S, et al. Prevalence, characteristics and clinical diagnosis of maturity onset diabetes of the young due to mutations in HNF1A, HNF4A, and glucokinase: results from the SEARCH for Diabetes in Youth. J Clin Endocrinol Metab. 2013;98(10):4055-62.

154. Hassanein M, Abdelgadir E, Bashier A, et al. The role of optimum diabetes care in form of Ramadan focused diabetes education, flash glucose monitoring system and pre-Ramadan dose adjustments in the safety of Ramadan fasting in high risk patients with diabetes. Diabetes Res Clin Pract. 2019;150:288-95.

155. Leff DR, Heath D. Surgery for obesity in adulthood. BMJ. 2009;339:b3402.

156. Al-Ozairi E, Al Kandari J, AlHaqqan D, AlHarbi O, Masters Y, Syed AA. Obesity surgery and Ramadan: a prospective analysis of nutritional intake, hunger and satiety and adaptive behaviours during fasting. Obes Surg. 2015;25(3):523-9.

157. Trierweiler H, Kisielewicz G, Hoffmann Jonasson T, Rasmussen Petterle R, Aguiar Moreira C. Zeghbi
Cochenski Borba V. Sarcopenia: a chronic complication of type 2 diabetes mellitus. Diabetol Metab Syndr. 2018;10(1):25.

158. Laatar R, Baccouch R, Borji R, Kachouri H, Rebai H, Sahli S. Ramadan fasting effects on postural control in the elderly: a comparison between fallers and non-fallers. J Relig Health. 2019;58(1):28-40.

159. Patel M, Gomez S, Berg S, et al. Effects of 24-h and 36-h sleep deprivation on human postural control and adaptation. Exp Brain Res. 2008;185(2):165-73.

160. Mir G, Sheikh A. 'Fasting and prayer don't concern the doctors ... they don't even know what it is': communication, decision-making and perceived social relations of Pakistani Muslim patients with long-term illnesses. Ethn Health. 2010;15(4):327-42.

161. Devendra D, Gohel B, Bravis V, et al. Vildagliptin therapy and hypoglycaemia in Muslim type 2 diabetes patients during Ramadan. Int J Clin Pract. 2009;63(10):1446-50.

162. Al Sifri S, Basiounny A, Echtay A, et al. The incidence of hypoglycaemia in Muslim patients with type 2 diabetes treated with sitagliptin or a sulphonylurea during Ramadan: a randomised trial. Int J Clin Pract. 2011;65(11):1132-40.

163. Halimi S, Levy M, Huet D, Quéré S, Dejager S. Experience with vildagliptin in type 2 diabetic patients fasting during ramadan in france: insights from the VERDI study. Diabetes Ther. 2013;4(2):385-98.

164. Shete A, Shaikh A, Nayeem KJ, et al. Vildagliptin vs sulfonylurea in Indian Muslim diabetes patients fasting during Ramadan. World J Diabetes. 2013;4(6):358-64.

165. Al-Arouj M, Hassoun AAK, Medlej R, et al. The effect of vildagliptin relative to sulphonylureas in Muslim patients with type 2 diabetes fasting during Ramadan: the VIRTUE study. Int J Clin Pract. 2013;67(10):957-63.

166. Malha LP, Taan G, Zantout MS, Azar ST. Glycemic effects of vildagliptin in patients with type 2 diabetes before, during and after the period of fasting in Ramadan. Ther Adv Endocrinol Metab. 2014;5(1):3-9.

167. Khaled BM, Belbraouet S. Effect of Ramadan fasting on anthropometric parameters and food consumption in 276 type 2 diabetic obese women. Int J Diabetes Dev Ctries. 2009;29(2):62-8.

168. Bener A, Al-Hamaq AO, Öztürk M, et al. Effect of ramadan fasting on glycemic control and other essential variables in diabetic patients. Ann Afr Med. 2018;17(4):196-202. 